Hydrol. Earth Syst. Sci., 17, 1765-1781, 2013

www.hydrol-earth-syst-sci.net/17/1765/2013/

doi:10.5194/hess-17-1765-2013

(C) Author(s) 2013. CC Attribution 3.0 License.

\title{
Elusive drought: uncertainty in observed trends and short- and long-term CMIP5 projections
}

\author{
B. Orlowsky and S. I. Seneviratne \\ Institute for Atmospheric and Climate Science, ETH Zurich, Universitaetsstr. 16, 8092 Zurich, Switzerland \\ Correspondence to: B. Orlowsky (boris.orlowsky@env.ethz.ch)
}

Received: 23 November 2012 - Published in Hydrol. Earth Syst. Sci. Discuss.: 18 December 2012

Revised: 11 April 2013 - Accepted: 16 April 2013 - Published: 7 May 2013

\begin{abstract}
Recent years have seen a number of severe droughts in different regions around the world, causing agricultural and economic losses, famines and migration. Despite their devastating consequences, the Standardised Precipitation Index (SPI) of these events lies within the general range of observation-based SPI time series and simulations from the 5th phase of the Coupled Model Intercomparison Project (CMIP5). In terms of magnitude, regional trends of SPI over the last decades remain mostly inconclusive in observationbased datasets and CMIP5 simulations, but Soil Moisture Anomalies (SMAs) in CMIP5 simulations hint at increased drought in a few regions (e.g., the Mediterranean, Central America/Mexico, the Amazon, North-East Brazil and South Africa). Also for the future, projections of changes in the magnitude of meteorological (SPI) and soil moisture (SMA) drought in CMIP5 display large spreads over all time frames, generally impeding trend detection. However, projections of changes in the frequencies of future drought events display more robust signal-to-noise ratios, with detectable trends towards more frequent drought before the end of the 21st century in the Mediterranean, South Africa and Central America/Mexico. Other present-day hot spots are projected to become less drought-prone, or display non-significant changes in drought occurrence. A separation of different sources of uncertainty in projections of meteorological and soil moisture drought reveals that for the near term, internal climate variability is the dominant source, while the formulation of Global Climate Models (GCMs) generally becomes the dominant source of spread by the end of the 21 st century, especially for soil moisture drought. In comparison, the uncertainty from Green-House Gas (GHG) concentrations scenarios is negligible for most regions. These findings stand in contrast to respective analyses for a heat wave index,
\end{abstract}

for which GHG concentrations scenarios constitute the main source of uncertainty. Our results highlight the inherent difficulty of drought quantification and the considerable likelihood range of drought projections, but also indicate regions where drought is consistently found to increase. In other regions, wide likelihood range should not be equated with low drought risk, since potential scenarios include large drought increases in key agricultural and ecosystem regions.

\section{Introduction}

The last decade has witnessed a number of severe drought events (Sheffield and Wood, 2011), e.g., the 2005 and 2010 Amazon droughts (both characterised as "100 yr events", Marengo et al., 2008; Lewis et al., 2011), the 2009-2011 drought years in China (Barriopedro et al., 2012; Sun and Yang, 2012), the North American "Texas" drought (since 2010, see Peterson et al., 2012; Seneviratne, 2012; Hoerling et al., 2012b), the Horn of Africa and Sahel droughts in 2011 (Lyon and DeWitt, 2012), and the recent decadelong drought in Australia (McGrath et al., 2012). In the recent Special Report by the Intergovernmental Panel on Climate Change (IPCC) on Managing the Risks of Extreme Events and Disasters to Advance Climate Change Adaptation (SREX), droughts are highlighted as one of the great challenges faced under climate change (IPCC, 2012; Seneviratne et al., 2012), in particular, for several hot spot regions that are consistently projected to be more strongly affected by drought in the future (e.g., the Mediterranean, Central America/Mexico, the Amazon, North-East Brazil and South Africa, IPCC, 2012; Orlowsky and Seneviratne, 2012). Several of the regions that have either experienced recent 
drought or are projected to be more strongly affected by drought in the future are important agricultural areas (e.g., Central Europe, parts of the US or India; see Monfreda et al., 2008), on which global food production may critically depend in the future (Foley et al., 2011). In addition, drought in the Amazon region has been highlighted as a possible tipping element of the climate system (Lenton et al., 2008), involving potential large feedbacks to the global carbon cycle (Friedlingstein et al., 2006; Poulter et al., 2010). Assessing the uncertainty and likely range of drought projections is, therefore, of key importance.

Measuring drought is non-trivial, and different drought indices have been used for different types of drought (LloydHughes and Saunders, 2002; Burke and Brown, 2008; Sheffield and Wood, 2011; Sheffield et al., 2012; Seneviratne et al., 2012). Meteorological drought, defined as precipitation deficits, can be quantified by the Standardised Precipitation Index (SPI, McKee et al., 1993) which we use in our study. Soil moisture drought (which is often termed "agricultural drought") is concerned with soil water availability, which we address through the analysis of Soil Moisture Anomalies (SMAs). Hydrological drought, which refers to low river flows and is, for example, of importance for water resources management (Stahl et al., 2010, 2012), is not addressed in our study. Depending on the chosen type and index of drought, changes of drought conditions in observation-based datasets and future projections by Global Climate Models (GCMs) differ substantially (Burke and Brown, 2008; I. H. Taylor et al., 2012). Recent studies (Dai, 2013; Sheffield et al., 2012) on observed global drought changes over the 20th century also find contradictory results, depending on the investigated indices.

In this paper, we aim to complement these studies by analysing the most up-to-date ensemble of GCM simulations from the 5th phase of the Coupled Model Intercomparison Project (CMIP5) together with observation-based datasets. In particular, we analyse historical and future changes of meteorological and soil moisture drought in several hot spot regions and provide a comprehensive discussion of the related uncertainties, depending on different drought indices, observation-based datasets, GCM simulations and future Green-House Gas (GHG) concentrations scenarios.

After introducing the employed data and indices, we first identify drought hot spots by compiling information on general drought exposure, land use and future drought projections (Sect. 2). For these hot spots, after a global robustness assessment of drought trends, we investigate the recent variations in meteorological and soil moisture drought in observation-based datasets and GCM simulations, analysing both the magnitude and frequency of the events (Sect. 3). Projected future drought trends and their likelihood range in CMIP5 projections are analysed in Sect. 4, including an assessment of the relative uncertainty contributions of internal variability, GCM formulation and GHG concentrations scenario to the total projection spread. A corresponding analysis is performed for a heat wave index to provide a benchmarking for the drought uncertainties. Section 5 summarises our findings and their implications.

\section{Data, indices and hot spots of drought}

\subsection{Data}

\subsubsection{CMIP5}

The internationally coordinated sets of CMIP5 GCM experiments provide climate simulations of historical and future periods with different GHG concentrations scenarios. The ensemble constitutes one of the main data sources for the upcoming 5th Assessment Report, AR5, by the IPCC. We use monthly data from the CMIP5 historical and three future Representative Concentrations Pathways experiments (RCP2.6, RCP4.5 and RCP8.5, see Moss et al., 2010), available at http://cmip-pcmdi.llnl.gov/index.html. The historical runs with observed GHG forcing finish in 2005 and the RCP experiments start in 2006, representing a peak-and-decline (RCP2.6), a stabilisation-without-overshoot (RCP4.5) and a rising (RCP8.5) GHG concentrations scenario, respectively. From each GCM, only one run is used (the rli1p1-run if available, where $\mathrm{r} 1$ denotes the first run of that GCM, given the first set of initial conditions, i1, and the first setting of physical parameters, p1, see Taylor et al., 2011; K. E. Taylor et al., 2012), and only if it is available both for the historical and the respective RCP experiments, and if it completely covers the 1950-2100 period. Table 1 indicates the available GCM projections at the time of analysis (October 2012).

\subsubsection{Observation-based datasets}

For the comparison of observed and GCM simulated droughts, we use three global monthly precipitation datasets of different spatial resolutions, based on station observations, remote-sensing data and combinations of these. We analyse the longest common period of all these datasets, 19792009. Observation-based monthly precipitation data is used from CRU TS3.1 (Climate Research Unit at the University of East Anglia, UK, Mitchell and Jones, 2005), covering 1901-2009 on a $0.5^{\circ}$ grid; CMAP (Climate prediction center Merged Analysis of Precipitation, from the NOAA, USA, Xie and Arkin, 1997), covering $1979-2009$ on a $2.5^{\circ}$ grid, and GPCP (Global Precipitation Climatology Project, Adler et al., 2003), covering $1979-2010$ on a $2.5^{\circ}$ grid.

\subsection{Indices of drought and heat waves}

\subsubsection{Time series of drought indices}

We use monthly time series of two standardised drought indices (see below) to quantify meteorological and soil moisture drought, respectively. Our analyses address both the 
Table 1. GCMs from the CMIP5 used in our study. Columns give GCM name, horizontal resolution and for each future GHG concentrations scenario the drought and heat wave indices that could be calculated from each GCM. SPI: Standardised Precipitation Index; SMA: Soil Moisture Anomalies; CDD: Consecutive Dry Days; WSDI: Warm Spell Duration Index. See Sect. 2 and the Supplement.

\begin{tabular}{|c|c|c|c|c|}
\hline GCM & Resolution & RCP2.6 & RCP4.5 & RCP8.5 \\
\hline BCC-CSM1.1 & Gaussian $128 \times 64$ & SPI, SMA & SPI, SMA & SPI, SMA, CDD \\
\hline BCC-CSM1.1(m) & Gaussian $320 \times 160$ & SPI & SPI, SMA & CDD \\
\hline CanESM2 & Gaussian $128 \times 64$ & SPI, SMA, WSDI & SPI, SMA, WSDI & SPI, SMA, CDD, WSDI \\
\hline CMCC-CESM & Gaussian $96 \times 48$ & & & CDD \\
\hline CMCC-CM & Gaussian $480 \times 240$ & & SPI, SMA, WSDI & SPI, SMA, WSDI \\
\hline CMCC-CMS & Gaussian $192 \times 96$ & & SPI, SMA & SPI, SMA, CDD \\
\hline CNRM-CM5 & Gaussian $256 \times 128$ & SPI, SMA, WSDI & SPI, SMA, WSDI & SPI, SMA, CDD, WSDI \\
\hline ACCESS1.0 & $192 \times 145$ & & SPI, SMA, WSDI & SPI, SMA, CDD, WSDI \\
\hline ACCESS 1.3 & $192 \times 145$ & & SPI, SMA & SPI, SMA, CDD \\
\hline CSIRO-Mk3.6.0 & Gaussian $192 \times 96$ & SPI, SMA, WSDI & SPI, SMA, WSDI & SPI, SMA, CDD, WSDI \\
\hline EC-EARTH & Gaussian $320 \times 160$ & SPI & WSDI & SPI,CDD \\
\hline FIO-ESM & Gaussian $128 \times 64$ & SPI & SPI & SPI \\
\hline BNU-ESM & Gaussian $128 \times 64$ & SPI, SMA, WSDI & SPI, SMA, WSDI & SPI, SMA, CDD, WSDI \\
\hline INM-CM4 & $180 \times 120$ & & SPI, SMA, WSDI & SPI, SMA, CDD, WSDI \\
\hline IPSL-CM5A-LR & $96 \times 96$ & SPI, SMA, WSDI & SPI, SMA, WSDI & SPI, SMA, CDD, WSDI \\
\hline IPSL-CM5A-MR & $144 \times 143$ & SPI, SMA, WSDI & SPI, SMA, WSDI & SPI, SMA, CDD, WSDI \\
\hline IPSL-CM5B-LR & $96 \times 96$ & & WSDI & WSDI \\
\hline FGOALS-g2 & $128 \times 60$ & SPI, SMA & SPI, SMA & SPI, SMA, CDD \\
\hline FGOALS-s2 & Gaussian $128 \times 108$ & SPI, SMA, WSDI & SPI, SMA, WSDI & SPI, SMA, CDD, WSDI \\
\hline MIROC5 & Gaussian $256 \times 128$ & SPI, SMA, WSDI & SPI, SMA, WSDI & SPI, SMA, CDD, WSDI \\
\hline MIROC-ESM & Gaussian $128 \times 64$ & SPI, SMA, WSDI & SPI, SMA, WSDI & SPI, SMA, CDD, WSDI \\
\hline MIROC-ESM-CHEM & Gaussian $128 \times 64$ & SPI, SMA, WSDI & SPI, SMA, WSDI & SPI, SMA, CDD, WSDI \\
\hline HadGEM2-CC & $192 \times 145$ & & & $\mathrm{CDD}$ \\
\hline HadGEM2-ES & $192 \times 145$ & WSDI & WSDI & CDD \\
\hline MPI-ESM-LR & Gaussian $192 \times 96$ & SPI, SMA, WSDI & SPI, SMA, WSDI & SPI, SMA, CDD, WSDI \\
\hline MPI-ESM-MR & Gaussian $192 \times 96$ & SPI, SMA, WSDI & SPI, SMA, WSDI & SPI, SMA, CDD, WSDI \\
\hline MRI-CGCM3 & Gaussian $320 \times 160$ & SPI, SMA, WSDI & SPI, SMA, WSDI & SPI, SMA, CDD, WSDI \\
\hline GISS-E2-H-CC & $144 \times 90$ & & SPI, SMA & \\
\hline GISS-E2-R & $144 \times 90$ & SPI, SMA & SPI, SMA, WSDI & SPI, SMA \\
\hline GISS-E2-R-CC & $144 \times 90$ & & SPI, SMA & \\
\hline CCSM4 & $288 \times 192$ & SPI, SMA & SPI, SMA & SPI, SMA, CDD \\
\hline NorESM1-M & $144 \times 96$ & SPI, SMA, WSDI & SPI, SMA, WSDI & SPI, SMA, CDD, WSDI \\
\hline NorESM1-ME & $144 \times 96$ & SPI, SMA & SPI, SMA & SPI, SMA \\
\hline HadGEM2-AO & $192 \times 145$ & SPI & SPI & SPI \\
\hline GFDL-CM3 & $144 \times 90$ & SPI,WSDI & SPI & SPI,CDD, WSDI \\
\hline GFDL-ESM2G & $144 \times 90$ & SPI, SMA, WSDI & SPI, SMA, WSDI & SPI, SMA, CDD, WSDI \\
\hline GFDL-ESM2M & $144 \times 90$ & SPI, SMA, WSDI & SPI, SMA, WSDI & SPI, SMA, CDD, WSDI \\
\hline CESM1(BGC) & $288 \times 192$ & & SPI, SMA, WSDI & SPI, SMA, CDD, WSDI \\
\hline CESM1(CAM5) & $288 \times 192$ & SPI & SPI & SPI, SMA \\
\hline
\end{tabular}

magnitude of drought (that is, the absolute values of the respective indices) and frequencies of drought, determined by the number of months per year in which an index falls below a certain threshold. These frequencies are estimated from running $10 \mathrm{yr}$ windows.

The Standardised Precipitation Index (SPI) is a commonly used index of meteorological drought (e.g., McKee et al., 1993; Lloyd-Hughes and Saunders, 2002; Heim, 2002; Hirschi et al., 2011; Mueller and Seneviratne, 2012; Seneviratne et al., 2012) characterising precipitation deficits or surpluses over different time scales. Here we use the
12 month time scale (SPI12) to account for long-term drought on the annual time scale, which is the time scale of the globally most severe drought events of the last decades, mentioned at the beginning of Sect. 1 (see also Sheffield and Wood, 2011, who lists severe droughts over the 20th century, most of them extending over one to several years). However, regions like Europe usually experience drought on shorter time scales of several months. Therefore, we additionally provide an analysis of the 3 month time scale (SPI3) for comparison in the Supplement. 
The SPI12 (and analogously SPI3) is computed as follows (see Lloyd-Hughes and Saunders, 2002, for details). For each month, the precipitation over the preceding 12 (3) months is summed. Then a two-parameter Gamma distribution of cumulative probability, $\Gamma_{\alpha, \beta}$, is fitted to the strictly positive 12 (3) month sums, such that the probability of a non-zero precipitation sum exceeding a certain value $x$ corresponds to $\Gamma_{\alpha, \beta}(x)$. We estimate shape parameter $\alpha$ and scale parameter $\beta$ with a maximum likelihood approach. If the estimation does not converge, $\alpha$ and $\beta$ are approximated using empirical relations (Lloyd-Hughes and Saunders, 2002). Accounting for 12 (3) month periods of no precipitation, occurring at a frequency $q$, the total cumulative probability distribution of a precipitation sum exceeding $x, H(x)$, becomes

$H(x)=q+(1-q) \Gamma_{\alpha, \beta}(x)$.

In the last step, a precipitation sum $x$ is assigned to its corresponding SPI value by computing the quantile $q_{N_{(0,1)}}$ which under the standard normal distribution with mean 0 and standard deviation $1, N_{0,1}$, corresponds to $H(x)$,

$x \rightarrow q_{N_{(0,1)}}(H(x))$.

The SPI of a precipitation sum $x$, thus, corresponds to the quantile of the standard normal distribution which is assigned by preserving the probability of the original precipitation sum, $H(x)$. By construction, the SPI centres at 0 with a standard deviation of 1 . Here, for all datasets, the Gamma distribution is fitted to the monthly sums of the 1979-2009 period for a consistent comparison with the observation-based datasets.

Monthly Soil Moisture Anomalies (SMAs, referring to the water content of the entire soil column) as an index of soil moisture (agricultural) drought are calculated with respect to the 1979-2009 monthly means and standardised by the monthly 1979-2009 standard deviations,

$\mathrm{SMA}_{y, m}=\left(\mathrm{SM}_{y, m}-\mu_{\mathrm{m}}\right) / \sigma_{\mathrm{m}}$,

where $y$ and $m$ denote any year and month, $\mathrm{SM}_{y, m}$ the corresponding soil moisture, while $\mu_{\mathrm{m}}$ and $\sigma_{\mathrm{m}}$ denote the mean and standard deviation of the soil moisture of month $m$ calculated over the 1979-2009 period. This standardisation accounts for the large spread of soil moisture variabilities in the GCMs due to different land-surface schemes, soil depths and layers, etc. (Orlowsky and Seneviratne, 2012) and ensures direct comparability with the SPI12, which is standardised over the same period. Note that the term "agricultural drought" is connotated with more dimensions than just the physical quantification through soil moisture, e.g., drought exposure of farmers and their adaptive capacity. In addition, soil moisture affects several other systems beside agricultural areas, such as forests, grassland and also built environment. For this reason, we use here the term "soil moisture drought" rather than "agricultural drought" (see also Seneviratne et al., 2012).
While for SPI at least a rough evaluation of the historical GCM simulations can be performed by comparing with observation-based datasets (Sect. 2.1), to date no suitable long-term observation-based data is available for (root-zone) soil moisture. Changes in GCM projected SMAs are, therefore, only indicative of actual changes and in particular their magnitudes should be interpreted with care. Note that the time scales of 1 month SMAs and SPI3/SPI12 differ. However, soil moisture typically exhibits a memory of several months (Dirmeyer et al., 2009; Orth and Seneviratne, 2012), thereby integrating precipitation comparably at least to SPI3 (in addition to integrating the effects of evapotranspiration). Moreover, projected changes in drought often display yearto-year carry-over effects (e.g., Wang, 2005), thus, possibly covering even longer time scales. Analysing both SPI3 and SPI12 together will help to detect cases, if any, where the temporal scale mismatch between SMA and SPI could be problematic.

Merely for comparison of CMIP5 with its predecessor CMIP3 in Sect. 2.3 (see Fig. S1 in the Supplement), we additionally use the Consecutive Dry Days Index (CDD, e.g., Tebaldi et al., 2006; Orlowsky and Seneviratne, 2012), based on daily precipitation data from GCM simulations of the CMIP5 and CMIP3 ensembles.

\subsubsection{Heat wave index}

To put the uncertainty of drought quantification and projection into perspective, similar analyses are performed for a standard heat wave index. The Warm Spell Duration Index (WSDI) counts the annual numbers of days that belong to spells of at least six days length at which the climatological 90th percentile of daily maximum temperatures is exceeded (Orlowsky and Seneviratne, 2012; Sillmann et al., 2013a). The index has been calculated for the CMIP5 simulations by Sillmann et al. (2013b) and has been downloaded for our study from http://www.cccma.ec.gc.ca/data/climdex/ index.shtml (last access: October 2012).

\subsection{Drought hot spots}

For our study we select drought hot spot regions starting from the hot spots identified in the SREX (IPCC, 2012; Seneviratne et al., 2012) and additionally using impact and land use data, as well as projections of future drought changes. These different data streams provide us with a nonexhaustive, but representative selection of regions, for which drought has already been relevant or will become potentially relevant in the future.

The maps in Fig. 1a, b show physical and economical drought exposure for the 1980-2001 period (data provided by the United Nations Environmental Program, UNEP, at http://preview.grid.unep.ch, last access: October 2012). Figure $1 \mathrm{c}, \mathrm{d}$ display the global distributions of crop and pasture lands of the year 2000 (Monfreda et al., 2008). The maps of 
a Physical exposure to drought

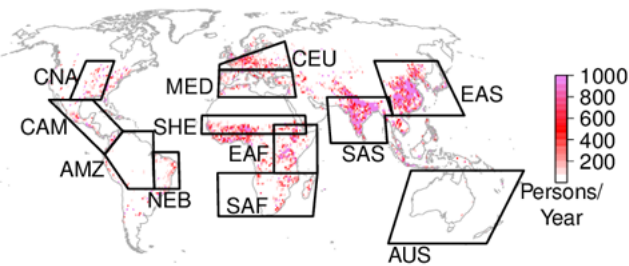

b Economic exposure to drought

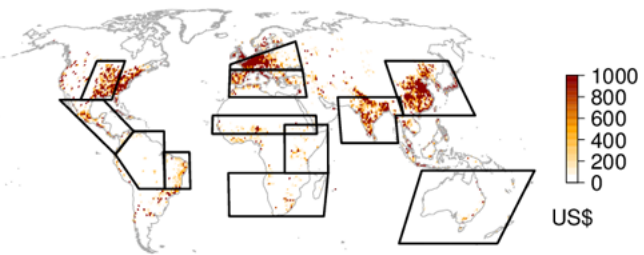

c Crop areas

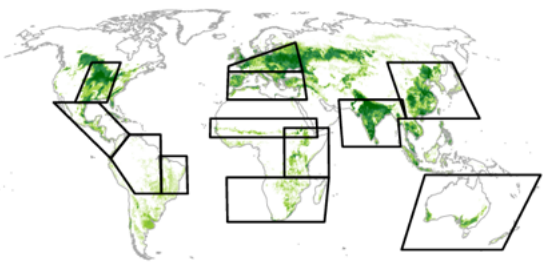

e SPI12 (2081-2100 vs. 1980-1999)

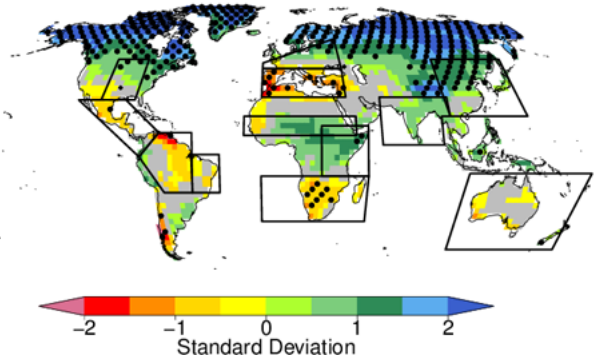

d Pasture areas

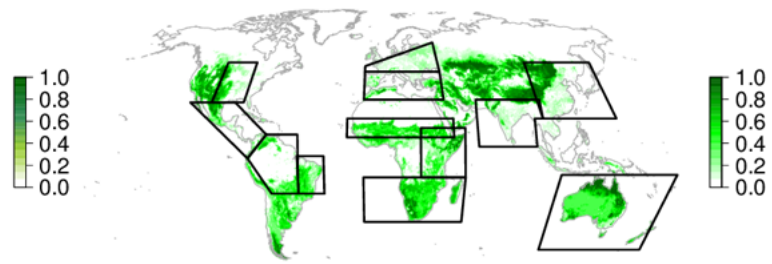

f SMA (2081-2100 vs. 1980-1999)

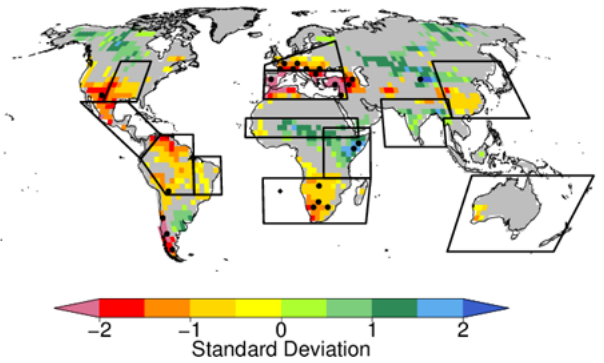

Fig. 1. Exposure to drought, land uses and future changes of drought in CMIP5 projections. (a) Physical exposure to drought measured by the number of persons exposed to drought per year over 1980-2001. (b) Economic exposure to drought in 1980-2001 measured by the expected average annual Gross Domestic Product GDP (2007 as the year of reference) exposed to drought (in US\$, year 2000 equivalent). (c) Crop areas as grid cell percentages for the year 2000. (d) Pasture areas as grid cell percentages for the year 2000. (e) Multi-GCM averages of multi-year average changes in 12 month Standardised Precipitation Index (SPI12) between present-day (1980-1999) and future (20812100), divided by the standard deviation of annual values with their linear trend over the 1961-2100 period removed. The GCM projections are based on the RCP8.5 GHG concentrations scenario. (f) As (e), but for changes in average Soil Moisture Anomalies (SMA). Colour shading in (e) and (f) indicates at least $66 \%$ of the GCMs agreeing on the sign of change, additional stippling (black dots) indicates $90 \%$ agreement. Gray shading indicates less than $66 \%$ GCM agreement on the sign, and if stippled (black diamonds), consistent small changes (at least $66 \%$ of the GCMs display changes smaller than half a standard deviation). Increased drought is indicated with yellow-red shading. Outlined regions in all maps indicate the hot spots that are analysed in our study.

physical and economical exposure and the crop land distribution show overlap in many regions, quantified for instance by the fractions of grid cells where two maps concurrently show values above the 66-percentile, compared to the grid cells where at least one of the two maps is above the 66percentile. These fractions range between $27 \%$ for crop land vs. economical exposure and $50 \%$ for economical vs. physical exposure. The patterns are naturally all closely related to the population density (also available from UNEP, not shown). Correspondingly, pasture areas are found in different regions, filling some of the gaps left by crop agriculture (the fraction of grid cells concurrently above the 66-percentile is $9 \%$ ). Regional hot spots of drought exposure and/or intense agricultural use include Central Europe (CEU) and the Mediterranean (MED), Central North America (CNA) and
Central America/Mexico (CAM), North-East Brazil (NEB), South Asia (SAS), East Asia (EAS, mostly China), the Sahel (SHE), and Eastern and Southern Africa (EAF and SAF, respectively). Australia (AUS) experienced until recently a decade-long drought (McGrath et al., 2012), which is not captured by the exposure data. Although not being exhaustive, this selection combines hot spots identified in the SREX (IPCC, 2012; Seneviratne et al., 2012) with further data streams and provides a representative selection of regions which are affected by drought changes in different ways.

Future projections of two drought indices in the CMIP5 ensemble, the 12 month Standardised Precipitation Index (SPI12) and Soil Moisture Anomalies (SMA, see Sect. 2 for both) show that some of these hot spots are consistently projected to become even drier during the 21 st century 
(Fig. 1e, f displays CMIP5 ensemble averages after interpolating individual GCM patterns to a Gaussian T42 grid of approximately $1.8^{\circ}$ resolution). This holds, in particular, for the Mediterranean region (MED, ensemble median of the regional average change of SPI12: -1.1 ), South Africa (SAF, median average change of SPI12: -0.53 ) and Central America/Mexico (CAM, median average change of SPI12: $-0.41)$. Further regions of aggravating drought include the Amazon (AMZ, median average change of SPI12: -0.33 ) and North East Brazil (NEB, median average change of SPI12: -0.48). On the other hand, some of the drought hot spots of the recent past are projected to become wetter, e.g., East Africa (EAF, median average change of SPI12: +0.94), the Sahel (SHE, median average change of SPI12: +0.53 ) and South Asia (SAS, median average change of SPI12: +0.73 ). This general pattern is found similarly for RCP2.6 and RCP4.5 (not shown), although RCP8.5 tends to produce stronger changes.

Note that the future changes of meteorological and soil moisture drought from the CMIP5 projections are consistent with the projections of the preceding CMIP3 ensemble (Supplement Fig. S1; see also Orlowsky and Seneviratne, 2012; Seneviratne et al., 2012). All regions selected in this section are analysed in the remainder of the paper.

\section{Drought changes of the recent past}

\subsection{Robustness of global change patterns}

In a recent study, Sheffield et al. (2012) computed trends in the commonly used Palmer's Drought Severity Index (PDSI) using two alternative potential evaporation formulations (the Thornthwaite formulation, Thornthwaite, 1948, and the Penman-Monteith formulation, Monteith, 1965) over the 1950-2008 period, derived from an observation-based dataset. It finds several regions of significantly increased drought with both potential evapotranspiration formulations, most notably in East Asia, Central and Sahelian Africa, Central and Southern Europe and Eastern Australia. These regional results also agree with the recent study by Dai (2013), although the two studies do not agree regarding trends in the global area affected by drought (Sheffield et al., 2012; Seneviratne, 2012). Here we complement the analyses of Sheffield et al. (2012) and Dai (2013) by assessing the robustness of trends in CMIP5 simulations of SPI12 and SMA over two periods, 1950-2009 and 1979-2009. For the latter and SPI12, trends from the three observation-based precipitation datasets CRU, CMAP and GPCP (Sect. 2) are included in the analysis.

We assess trends from linear least-squares regression of annual averages of SPI12 and SMA against time and evaluate the statistical significance of the trend being different from zero by the standard $t$ test. This test is known to be sensitive to auto-correlation in the time series, and spatial correlations further compromise its interpretability (see e.g., Stahl et al., 2010, for a discussion of typical pitfalls when assessing trends in hydrological time series). Although we do not address them directly, we try to circumvent these issues by setting a rather demanding significance level of $0.5 \%$. Trends and $p$ values of the linear regression on the original GCM grids are interpolated to a common $0.5^{\circ}$ grid by nearest-neighbour assignment prior to the assessment of agreeing significant trends. The interpolation to a grid with finer resolution than the GCM grids correctly preserves the information of the $p$ values at all locations, which would be compromised by interpolation to a coarser grid.

Figure 2 assesses the agreement on drought trends in the historical CMIP5 simulations. In order to maximise the overlap of years between observation-based datasets and CMIP5 simulations, the years after 2005 are taken from the continuing runs into the RCP8.5 GHG concentrations scenario, which compares best to the observed GHG concentrations of these years (compare Moss et al., 2010; Van Vuuren et al., 2011). For SPI12, the only extended land regions of rather consistent trends are in the high latitudes, where up to a half of the 32 GCMs indicate significant positive trends (Fig. 2a, c). The observation-based trends in Fig. 2c show only few patches with consistent trends, e.g., wetting in the high latitudes, neutral trends in mid-latitudes, drying patches in the sub tropics and wetting patches in the tropics, although it is difficult to support such a zonal generalisation from the analysis. This observation-based pattern is only in part agreeing with the CMIP5 pattern (although there is not much of a pattern in the first place). Note also that the observationbased pattern is by far less clear than the long-term 19251999 trend pattern found from zonal averaged precipitation anomalies in Zhang et al. (2007), which indicates that our $31 \mathrm{yr}$ period is probably too short to detect possible changes for large parts of the globe. However, in particular over parts of Eastern Asia and Africa, our observation-based trend pattern shows that the consistent areas of increase or decrease do not depend on latitude only, which hints at a limited value of the zonal average for that regional scale.

Results for SPI3 (Fig. S2 in the Supplement) shows patterns similar to the SPI12 analyses.

Recent global (Dai, 2013; Sheffield et al., 2012) and regional (with a focus on the Mediterranean and Europe, Hoerling et al., 2012a; Stahl et al., 2012) studies find more coherent trends patterns than displayed in our Fig. 2. This discrepancy may be related to several factors, including different hydrological variables or indices, different time periods and different ways of assessing the statistical significance of the trends. Taking these factors into account, our results do not contradict the patterns from other studies, but highlight the inherent ambiguity in quantifying such trends.

Overall, especially for the 1979-2009 period in Fig. 2c, d the CMIP5 patterns are dominated either by consistently no significant trends (white) or by contradicting signals (grey shading), which holds, in particular, for SMA, where only 
a SPI12 1950-2009 (CMIP5)

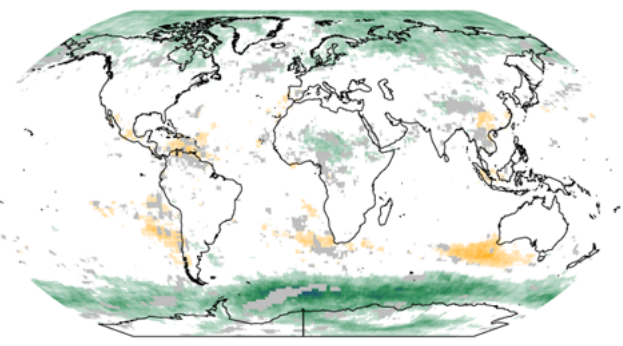

c SPI12 1979-2009 (CMIP5 \& observ.-based)

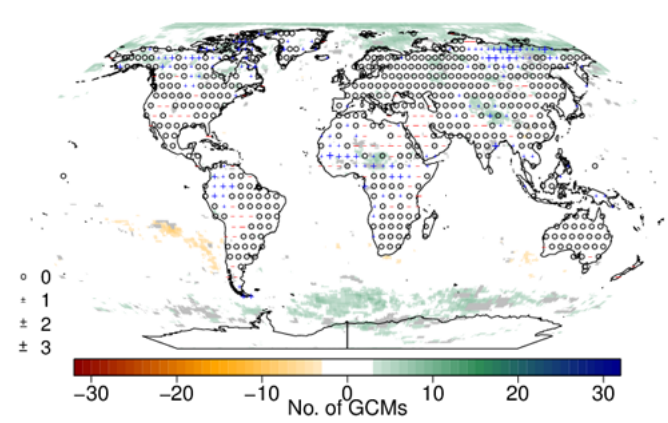

b SMA 1950-2009 (CMIP5)

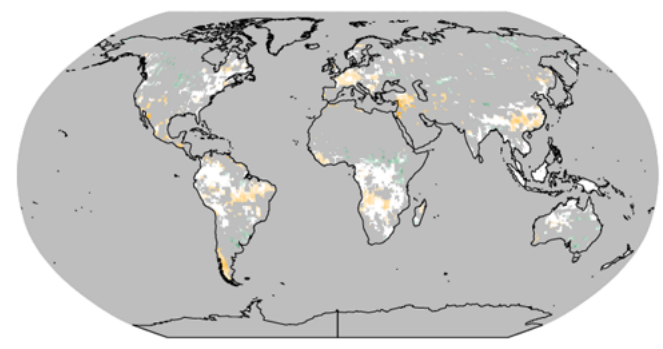

d SMA 1979-2009 (CMIP5)

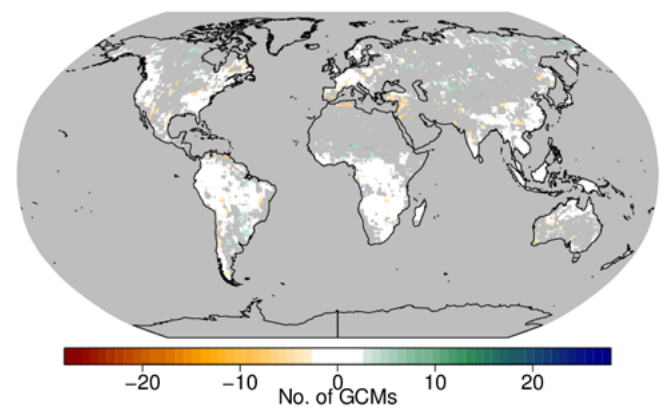

Fig. 2. Consistency of drought trends in two observational periods (observation-based datasets and CMIP5 GCM simulations) for SPI12 (a, c) and SMA $(\mathbf{b}, \mathbf{d})$. Colour shading is applied if the significant trends (evaluated at the $0.5 \%$ significance level) across the CMIP5 ensemble are all of the same sign and indicates the number of GCMs with significant trends (green-blue for positive/wetting, orange-red for negative/drying trends). White indicates regions where at least $90 \%$ of the GCMs show no significant trends (consistently no change). All other areas are grey. Symbols in (c) show the same for three observation-based SPI12 datasets. "o": none of the three datasets shows a significant trends; blue "+" and red "-" indicate purely significant positive/wetting and negative/drying trends, respectively; the size of the symbol indicates the number of agreeing observation-based datasets (see legend at c).

a few scattered patches show consistent drying trends in the CMIP5 simulations. Furthermore, for both indices consistent trends are only found in rather small subsets of the CMIP5 ensemble. We conclude that the detection of drought hot spots from trends in the observational period remains a significant challenge.

\subsection{Past changes of drought in selected hot spot regions}

In the remainder of this article, we present results from analysing the drought hot spots identified in Sect. 2. Given the many severe drought events in the last years, e.g., the "Texas" drought in Southern US and Mexico since 2010 (regions Central North America, CNA, and Central America/Mexico, CAM), the drought at the Horn of Africa in 2011 (region East Africa, EAF) and the China droughts 2009-2011 (region East Asia, EAS), obvious questions are whether these events are exceptional or within internal climate variability, whether drought magnitude or frequency has increased or decreased over the last decades, and whether there will be future changes.
Figure 3 displays time series of SPI12 from three observation-based datasets, averaged with grid cell area weighting over the land grid cells with centres in the identified hot spot regions. Shading indicates the range of the corresponding CMIP5 time series of the same regions and period. The conclusions for the recent past of all investigated regions are very similar. First, the three observationbased datasets correlate reasonably well, although the amplitudes are less consistent (Pearson's correlation coefficients average at 0.8 , with all correlation coefficients being above 0.6, except for some combinations in EAF and EAS, where they go down to approximately 0.4 ). Second, there are hardly any trends over this period, neither in the observation-based datasets nor in the GCM ensemble. A few very weak tendencies can be found, e.g., for MED (drying after approximately 1980) and CNA (wetting), but these are negligible in view of the large inter-annual variability both in the observationbased datasets and the GCMs and not significant statistically (see Fig. 2). The range of SPI12 values at this spatial aggregation is generally rather limited, hardly exceeding \pm 1 , even for the peak of the devastating Sahel (SHE) drought in the 1980s. Global trends towards increased dryness as found 
SPI12

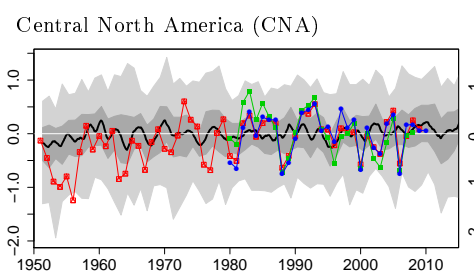

Central America/Mexico (CAM)

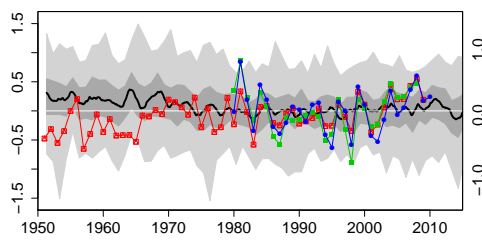

Amazonia (AMZ)

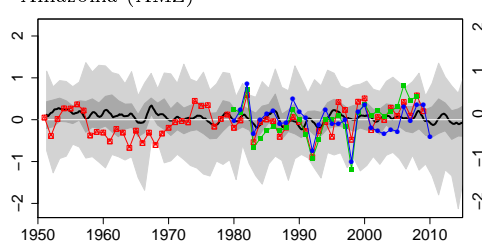

North-East Brazil (NEB)

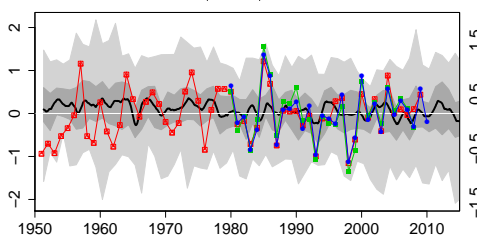

Central Europe (CEU)

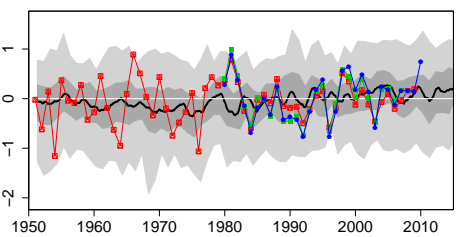

Mediterranean (MED)

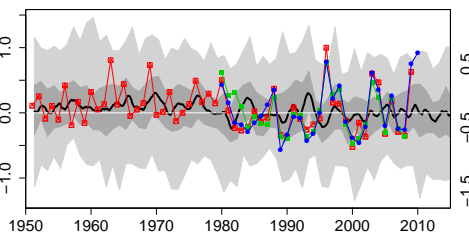

Sahel (SHE)

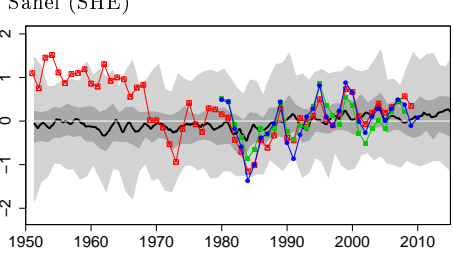

East Africa (EAF)

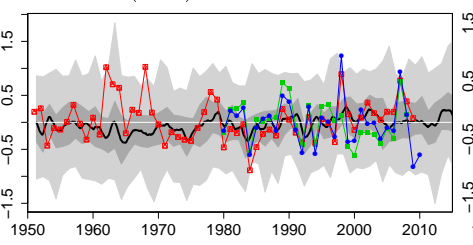

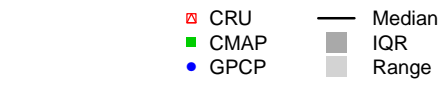

East Asia (EAS)

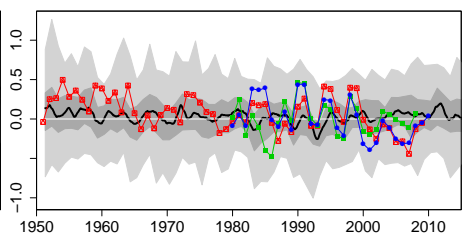

South Asia (SAS)

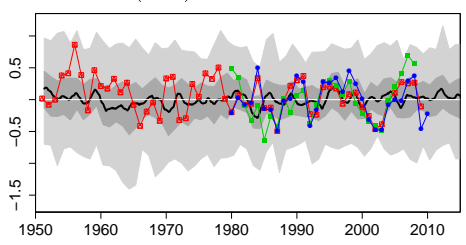

Australia (AUS)

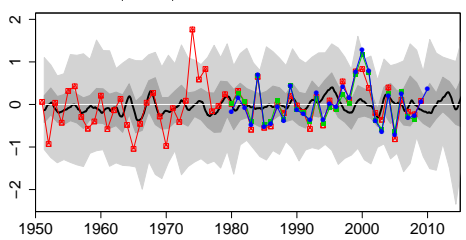

South Africa (SAF)

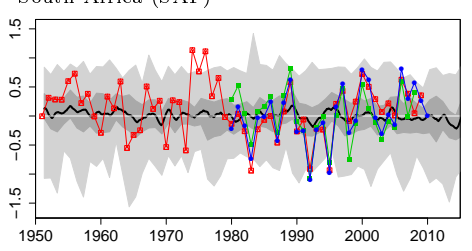

Fig. 3. Observation-based and CMIP5 simulated SPI12: annual averages of SPI12 values from three observation-based datasets (coloured lines) and median, inter-quartile range and total range across the CMIP5 ensemble (black line, dark grey and grey shading, respectively). Until 2005, CMIP5 data come from the historical simulations, after-wards, projections for the GHG concentrations scenario RCP8.5 are used. SPI1 values are calculated with respect to the 1979-2009 period for all datasets.

in Dai (2013) for the last decades are not reproduced by the SPI12 at this regional scale. Last, the dry years depicted by the SPI1 2 in the observation-based data always fall within the range of the GCM ensemble. Despite their sometimes devastating societal and economical effects, none of the major events mentioned in Sect. 1 appears as exceptional in these observation-based time series when compared to their overall range and the spread of the GCM ensemble.

A complementary analysis of the occurrence frequencies of months with SPI $12<-0.5$ in moving $10 \mathrm{yr}$ windows (representing only "mild drought" conditions, see Lloyd-Hughes and Saunders, 2002) is presented in Fig. 4. This threshold is not indicative of pronounced drought (a threshold of at least -1 , indicating "moderate drought", would be more meaningful), but the limited range of the time series over the observational period at this level of spatial aggregation requires such a low value for a robust occurrence frequency estimation. The obtained conclusions are basically the same as for the SPI1 2 magnitude. Only for the Mediterranean, North East
Brazil and for the years after approximately 1990 in South Africa, the GCM simulations seem to indicate increased meteorological drought, although this is not consistently found in the observation-based datasets. The volatility in some of the observation-based frequency series is due to the sometimes very few months with SPI $12<-0.5$.

The time series for SPI3 (Figs. S3 and S4 in the Supplement) lead to the same interpretations, the main difference being a slightly narrower range of the SPI3 magnitudes.

The corresponding analysis for SMA in the CMIP5 simulations (Figs. 5 and 6) displays more consistent tendencies, in particular for the frequencies of months with SMA $<-0.5$ standard deviations rather than SMA itself (see the MED, CAM, AMZ, NEB and SAF panels in Fig. 6 for increasing soil moisture drought). The extended drought in the Sahel (SHE) and its recovery since the 1980s (Sheffield and Wood, 2011) is also visible, which is interesting since the GCM simulations are driven by historical radiative forcing only (not including e.g., observed Sea Surface Temperatures, which are 
Frequency SPI12 <-0.5 (months/year)

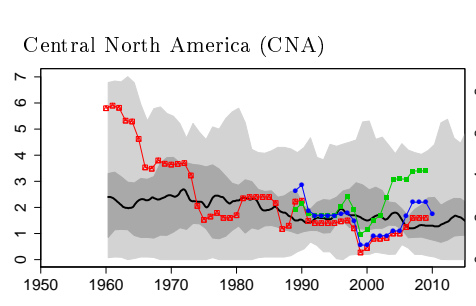

Central America/Mexico (CAM)

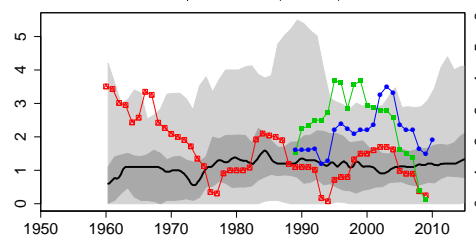

Amazonia (AMZ)

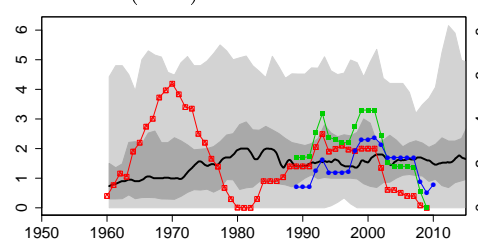

North-East Brazil (NEB)

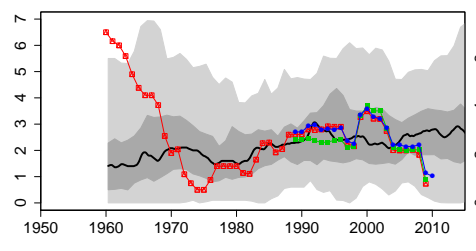

Central Europe (CEU)

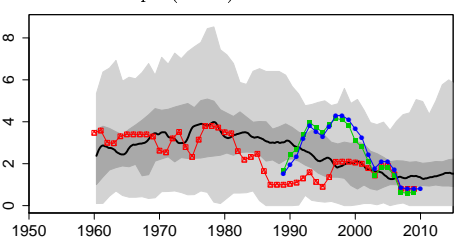

Mediterranean (MED)

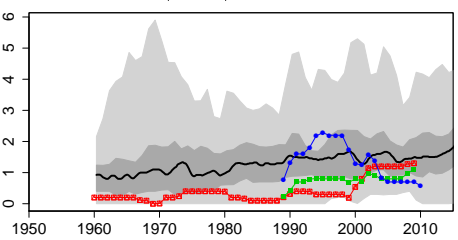

Sahel (SHE)

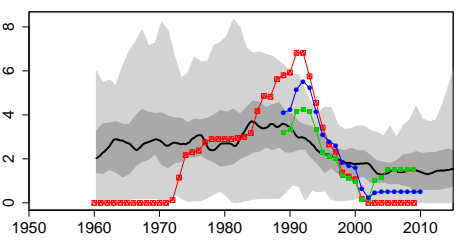

East Africa (EAF)

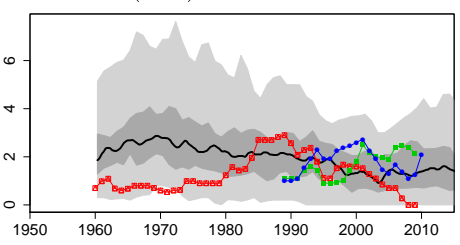

East Asia (EAS)
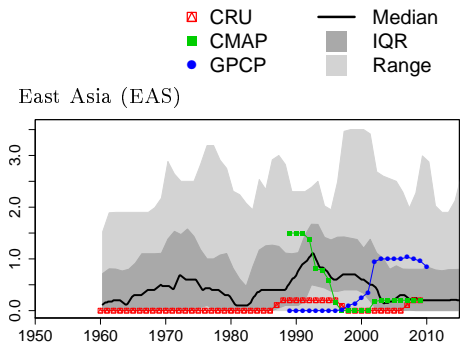

South Asia (SAS)

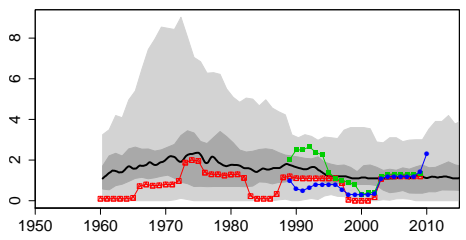

Australia (AUS)

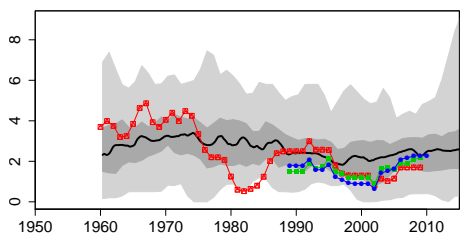

South Africa (SAF)

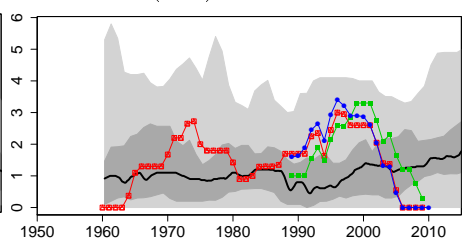

Fig. 4. As Fig. 3, for the occurrence frequencies of "mild drought" (SPI12<-0.5) in observation-based datasets and CMIP5 simulations, derived from $10 \mathrm{yr}$ moving windows. Frequencies are given as months per year.

known to control Sahel precipitation, see e.g., Held et al., 2005). Analysing potential links between the Sahel drought and the historical radiative forcing, however, is beyond the scope of our study.

Our analysis, thus, indicates that the drying in these regions is not due to decreases in (standardised) precipitation, but is linked to the effect of increased evapotranspiration, which can drive soil drying even if precipitation does not decrease (Seneviratne, 2012). Increases in runoff as an explanation for soil moisture depletion are less probable, as runoff in observations tends to decrease in regions where soil moisture decreases (Stahl et al., 2010, 2012). Furthermore, in the rather simple land surface modules of the CMIP5 GCMs, runoff depends on soil moisture availability and is, therefore, unlikely to increase when soil moisture decreases. The higher consistency for frequencies compared to magnitude may be related to physical limits of the system. For example, if a soil approaches dry-out, SMA cannot decrease any further, while the frequency of SMA below some threshold can still increase.
Although the threshold for the frequency analysis cannot be related to specific impacts directly in such a standardised framework, this does not compromise the finding that occurrence frequencies show clearer signals than magnitudes, although both for magnitudes and frequencies and in all investigated regions, the spread over the period is larger than the changes.

The few spots of systematic SMA decreases in Fig. 2 fall into the drying regions identified in Fig. 6, although their spatial extent does not cover the entire hot spot regions due to the masking for statistical significance.

Time series of top-layer soil moisture from a merged active and passive micro-wave remote-sensing dataset (Liu et al., 2012) display an unrealistic interannual variability (not shown) and are compromised by instrumentation changes over time. They are, therefore, omitted from our analyses. In the absence of any other reliable observation-based soil moisture dataset with global coverage (Seneviratne et al., 2010), a comparison between observed SMA and GCM simulations and their internal variability is not feasible at this stage. 
SMA
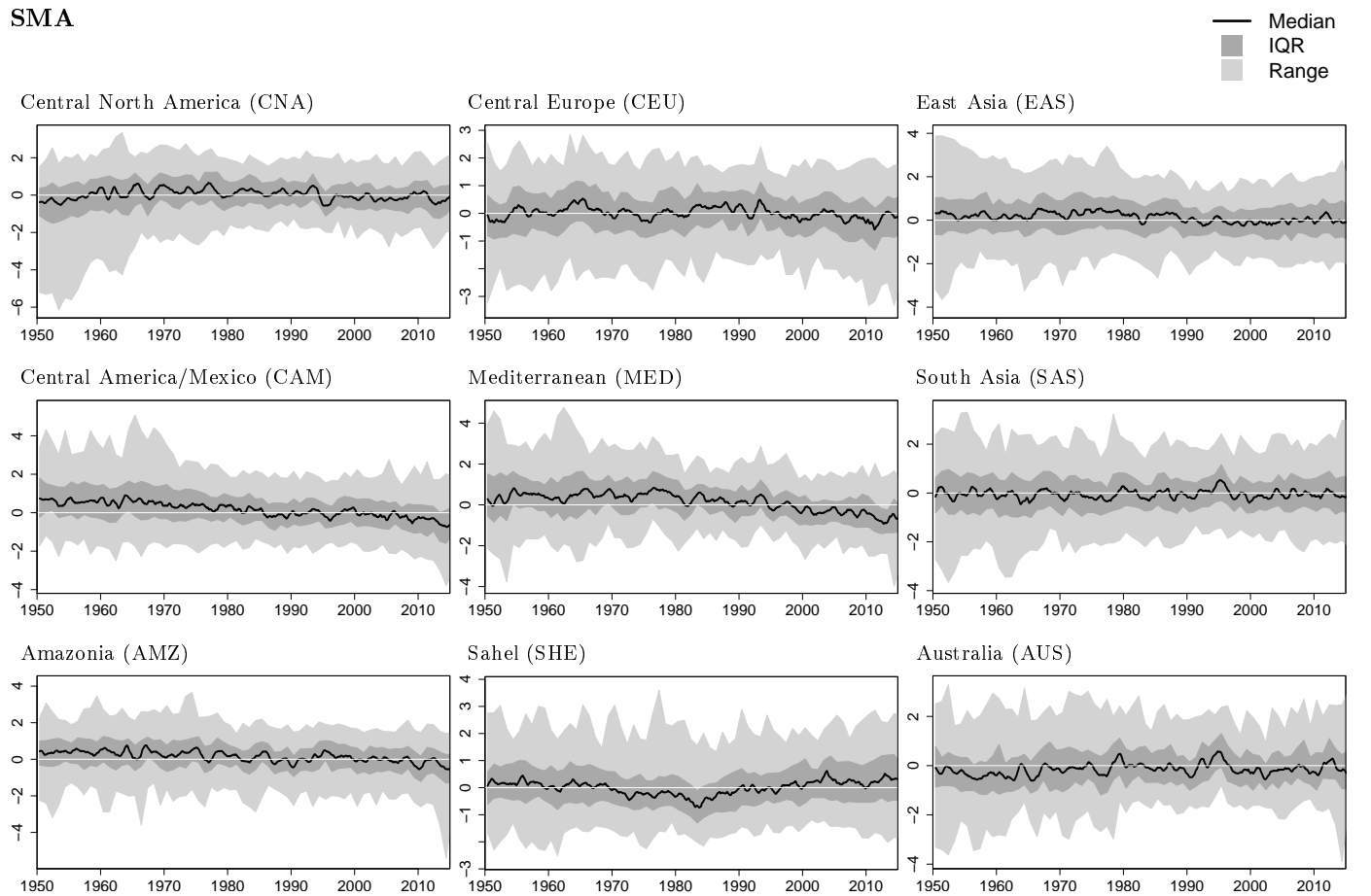

Sahel (SHE)
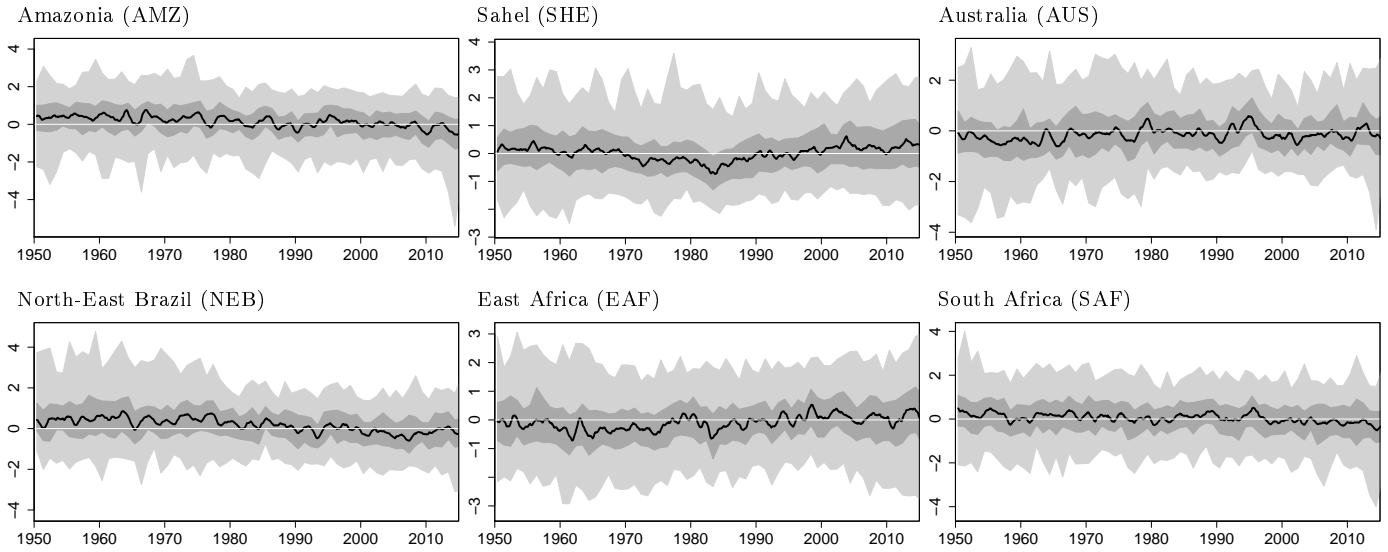

Fig. 5. CMIP5 simulated SMA: Median, inter-quartile range and total range across the CMIP5 ensemble of annual SMA averages (black line, dark grey and grey shading, respectively). Until 2005, CMIP5 data come from the historical simulations, after-wards, projections for the GHG concentrations scenario RCP8.5 are used. SMA values are calculated with respect to the 1979-2009 period for all datasets.

\section{Drought changes in future projections}

\subsection{Future changes of drought in selected hot spot regions}

In Fig. 7, we show future projections of SPI12 and SMA for six of the twelve hot spot regions. They share that the median SPI12 increases (Fig. 7a), with the clearest signals in the Asian and African regions (except for Sahel), some of them present-day drought hot spots (e.g., EAF, SAS and EAS, see Sect. 2.3). For these regions there is also a clear dependence on the GHG concentrations scenario, with the stronger scenarios coinciding with stronger changes. In contrast, the US and Europe have weaker signals. Soil Moisture Anomalies (SMA, see Fig. 7b) show a much larger GCM-ensemble spread, which includes both substantial increase and decreases of soil moisture. Taking SPI12 and SMA together, the clearest signal of wetting is found for the EAF region, in agreement with Shongwe et al. (2011). Central North America (CNA) and Central Europe (CEU) even suggest slight decreases of soil moisture for the majority of the GCMs, hinting at a stronger increase of evapotranspiration offsetting precipitation increases in these regions (Sheffield and Wood, 2008a, also find increases in the spatial extent of soil moisture drought in these regions in CMIP3 simulations, although small).

Note, however, that due to the lack of suitable data, GCM simulations of soil moisture cannot be constrained by observations and apparent trends must be interpreted as indicative rather than as realisation of physical reality. This is particularly relevant given the disagreement between different formulations of the widely used Palmer's Drought Severity Index (PDSI, Palmer, 1965; Wells et al., 2004; Sheffield et al., 2012) which is also considered as an index relevant to soil moisture drought (Sheffield and Wood, 2011).

In the remaining six hot spot regions, median SPI12 decreases to varying degrees (Fig. 8a), and soil moisture decreases accordingly (Fig. 8c). The Mediterranean (MED) displays the clearest decrease, followed by South Africa (SAF), Central America/Mexico (CAM) and the 


$$
\text { Frequency SMA }<-0.5 \text { (months/year) }
$$

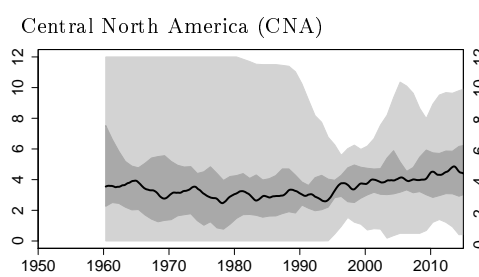

Central Europe (CEU)

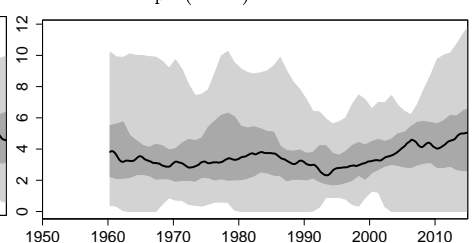

Central America/Mexico (CAM)

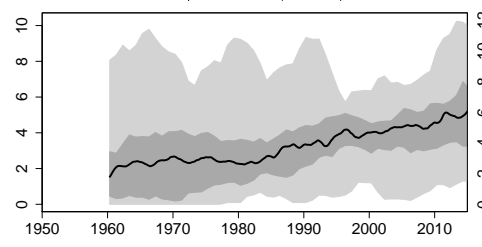

Mediterranean (MED)

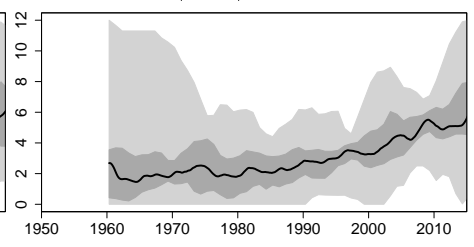

Sahel (SHE)
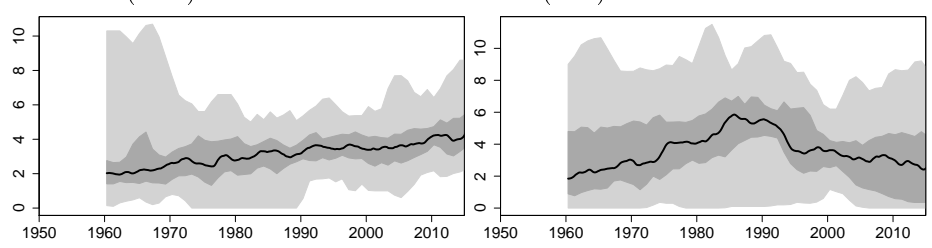

North-East Brazil (NEB)

East Africa (EAF)
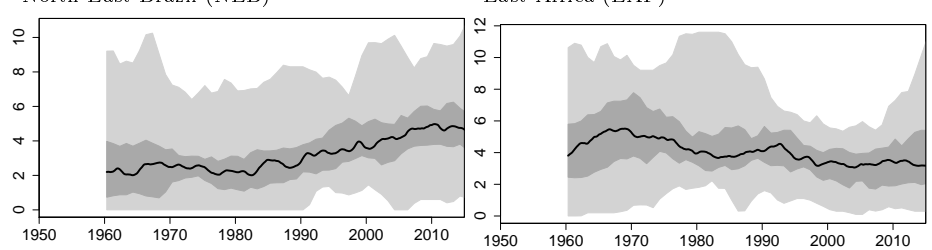

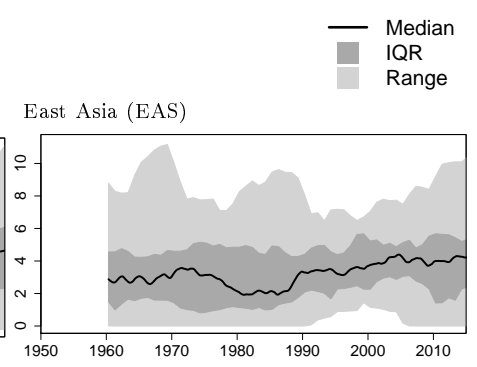

South Asia (SAS)

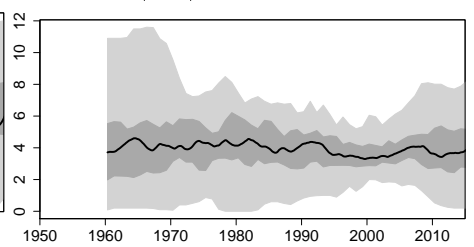

Australia (AUS)

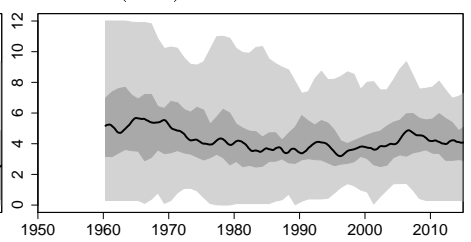

South Africa (SAF)

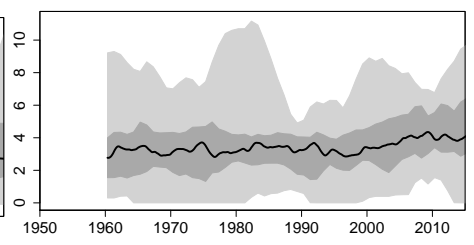

Fig. 6. As Fig. 5, for the occurrence frequencies of months with SMA $<-0.5$ in CMIP5 simulations, derived from 10 yr moving windows. Frequencies are given as months per year.
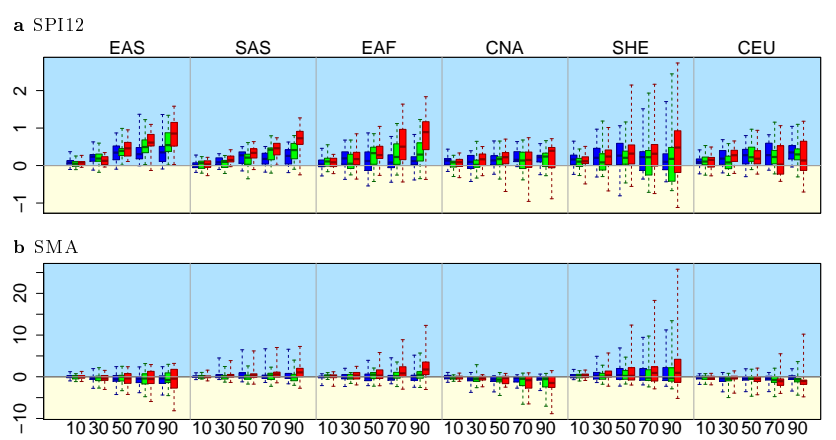

Fig. 7. Wetting regions in the 21 st century. (a) Box plots for $20 \mathrm{yr}$ average SPI12, regions where the median SPI12 increases. The numbers at the bottom-most $\mathrm{x}$-axis denote the central years in the 21 st century of the $20 \mathrm{yr}$ windows. Colours indicate the respective GHG concentrations scenario, blue: RCP2.6, green: RCP4.5 and red: RCP8.5. (b) like (a), but for Soil Moisture Anomalies (SMA). Changes are given as standard deviations with respect to 1979-2009 in both plots.
Amazon (AMZ), trends which are also found in the CMIP3 analyses in Sheffield and Wood (2008a); Orlowsky and Seneviratne (2012) and in a perturbed parameters experiment (I. H. Taylor et al., 2012). For North East Brazil (NEB) and Australia (AUS), even for the strongest changes in the 2090s under RCP8.5, the 0-change line is within the interquartile range of the ensemble, indicating substantial uncertainty about the sign of the future trend. The decrease of SMA over the historical period (Sect. 3.2 and Figs. 5 and 6) in North East Brazil (NEB) is less evident for the future. While changes of SMA reach higher amplitudes, they also display much larger ranges (note the different y-axes), suggesting on the one hand a stronger integrated response of the soil compared to precipitation alone, but also highlighting the considerable range in the representation of the related processes in the CMIP5 GCMs.

Trends are more visible when frequencies rather than magnitudes of drought are analysed, as Fig. 8b, d shows by the number of months per year in which the SPI $12<-1$ and SMA $<-1$, respectively, calculated for 


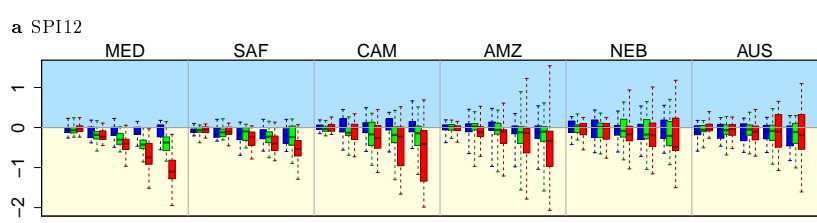

b Freq. SPI1 $<-1$ (months/year)

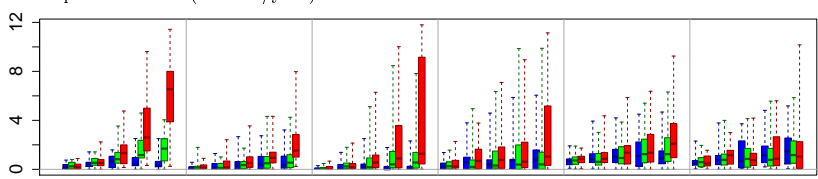

c SMA

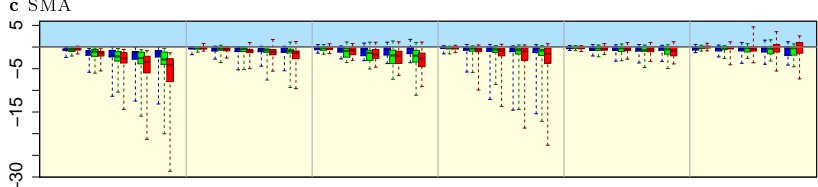

d Freq. SMA $<-1$ (months/year)

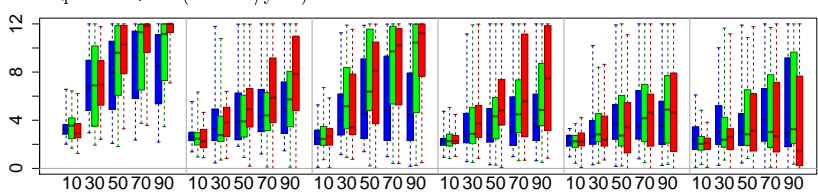

Fig. 8. Drying regions in the 21 st century. (a) Box plots for $20 \mathrm{yr}$ average SPI12, regions where the median SPI12 decreases. The numbers at the bottom-most $\mathrm{x}$-axis denote the central years in the 21 st century of the $20 \mathrm{yr}$ windows. Colours indicate the respective GHG concentrations scenario, blue: RCP2.6, green: RCP4.5 and red: RCP8.5. (b) Months per year in which SPI1 $<-1$. (c) and (d) Like (a) and (b), but for Soil Moisture Anomalies (SMA). Changes are given as standard deviations with respect to 1979-2009 in (a) and (c) and as months per year in (b) and (d).

moving $10 \mathrm{yr}$ windows. SPI $12<-1$ indicate at least "moderate drought" (see e.g., Lloyd-Hughes and Saunders, 2002), while SMA $<-1$ indicates one standard deviation below normal with respect to to the 1979-2009 period (see Sect. 2) and, in contrast to the historical analyses presented in Sect. 3.2, the future changes are large enough to perform the frequency analysis with this threshold.

Other findings correlate with the strength of the decreases. For example, in regions with small changes such as Australia (AUS), hardly any differentiation between the three GHG concentrations scenarios is visible, in contrast to the Mediterranean (MED). Changes also depend on time, generally with a monotonic increase. However, for the regions with strong changes, this dependence is nonlinear and indicative of the regions approaching a depleted state. For example, drought frequencies in SMAs in the Mediterranean (MED) saturate towards almost every month by the 2090s under the RCP8.5 scenario, a frequency which is also within the ensemble range of SPI12 projections for the Mediterranean (MED) and Central America/Mexico (CAM). "Moderate drought" (SPI1 $<-1)$ of the present day climate is projected as normal for the 2090s in these simulations. The
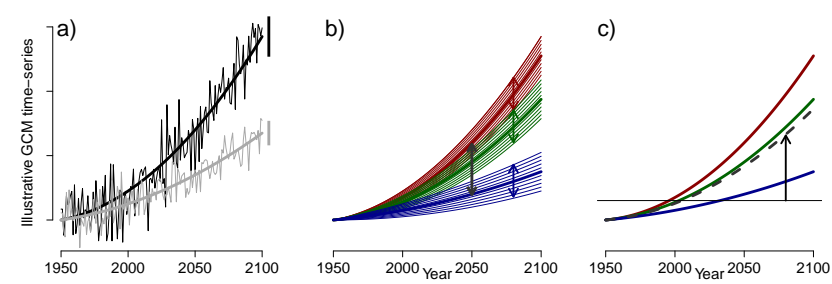

Fig. 9. Separation of the total ensemble uncertainty, $\sqrt{T_{y}}$, into relative contributions from internal variability, $V$, uncertainty due to GCM formulation, $M_{y}$, and GHG concentrations scenario, $S_{y}$, following Hawkins and Sutton (2009). (a) Two illustrative GCM time series (such as temperature or a drought index with a strong upward trend) and their 4th order polynomial fit. The bars to the right denote the time-independent variability of the annual residuals. Their average over all GCM series and GHG concentrations scenarios defines the internal variability, $V$. (b) Illustrative 4th order polynomial fits of GCM time series from three different GHG concentrations scenarios (colours blue, green, red, analogue to RCP2.6, RCP4.5 and RCP8.5 in Figs. 7 and 8). Thick lines denote the averaged time series of the series corresponding to each of the different GHG concentrations scenarios. Coloured arrows indicate the variability within each scenario at a given year. Their average defines the uncertainty due to GCM formulation, $M_{y}$, for that year. The grey arrow indicates the variability of the intra-scenario average time series at a given year. This variability defines the uncertainty due to GHG concentrations scenario, $S_{y}$. (c) The intra-scenario averages and their mean (black dashed line). The change signal of a given year, $G_{y}$, is defined as the change in this mean with respect to the level of the reference year 2006 (horizontal line). See text for details.

likelihood range of projected changes is generally wider for the high GHG concentrations scenario, see e.g., the SPI12 projections for Central America/Mexico (CAM).

Corresponding results for SPI3 reconfirm the findings for SPI12 (see Fig. S5 in the Supplement), although the projected changes are smaller compared to SPI12.

\subsection{Sources of uncertainty in drought projections}

To investigate the causes behind the large spread in future projections of meteorological and soil moisture drought, we separate the total uncertainty of the CMIP5 ensemble into contributions from internal variability, GCM formulation and GHG concentrations scenarios. To this end, we apply a modified version of the method proposed in Hawkins and Sutton (2009, see Fig. 9), using all available projections in the CMIP5 ensemble (as of October 2012) from the RCP2.6, RCP4.5 and RCP8.5 experiments (see Sect. 2.1). In a preparatory step, a 4th order polynomial is fitted to the annual values (e.g., annual average SMA) of each GCM simulated time series using least squares regression (Fig. 9a) to identify the long-term trend component of the time series. From this, 

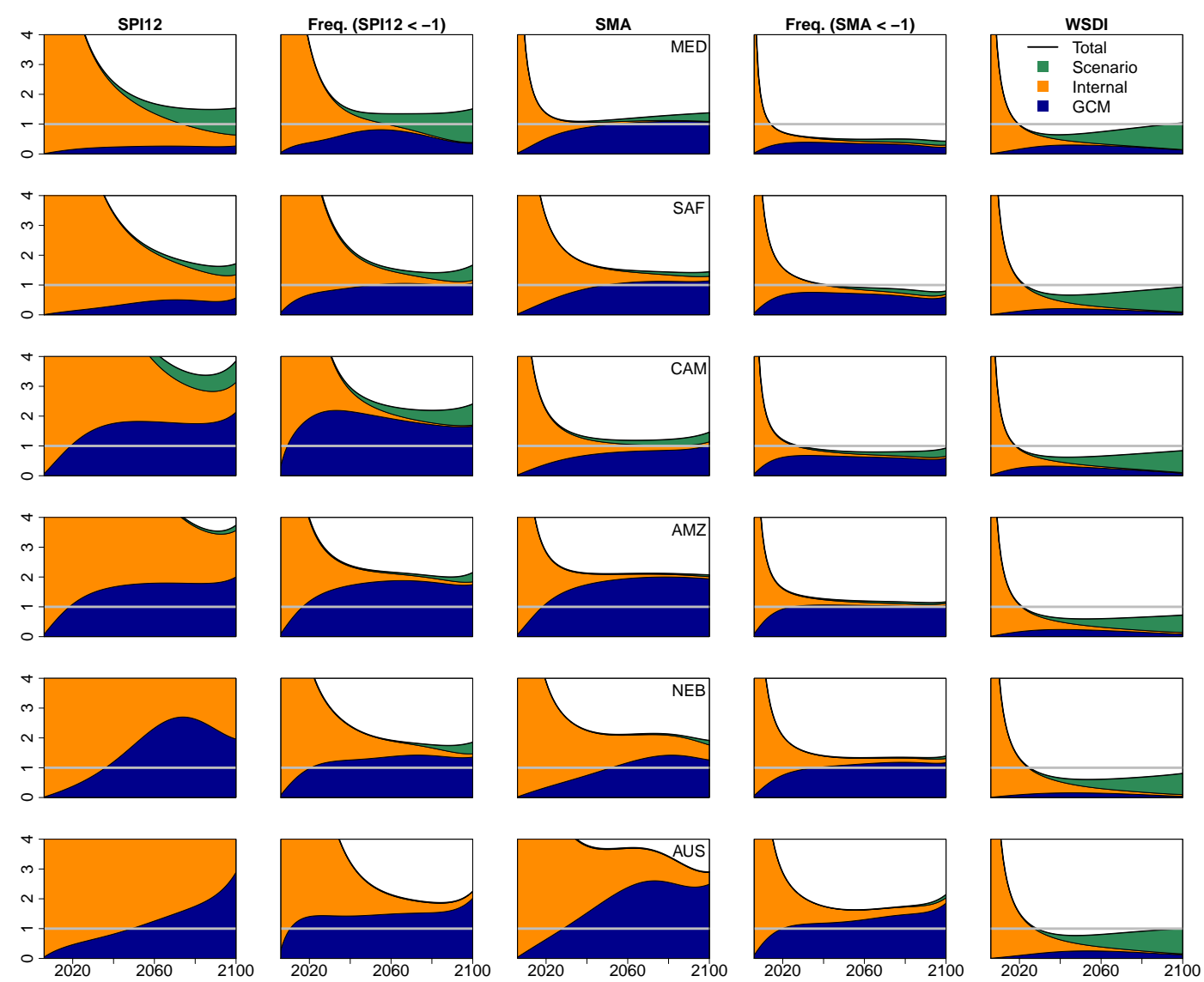

Fig. 10. Fractional uncertainty, defined as uncertainty divided by the change since $2006, F_{y}=\sqrt{T_{y}} / G_{y}$. Columns show $F_{y}$ for magnitude and frequency (months per year with values $<-1$, calculated from $10 \mathrm{yr}$ moving windows) of SPI12, SMA and a heat wave index (WSDI) for the analysed hot spot regions with decreasing median SPI12 (rows). Colours indicate the relative uncertainty contributions from GCM formulation $\left(M_{y}\right.$, blue), internal variability ( $V$, orange) and GHG concentrations scenarios $\left(S_{y}\right.$, green). See Fig. 9 and text for details.

- the time-independent internal variability, $V$, is defined as the multi-GCM and multi-scenario average over the variances of the annual residuals of the polynomial fit of each GCM series (Fig. 9a),

- the GCM or model uncertainty of a given year $y, M_{y}$, is the average over all GHG concentrations scenarios of the within-scenario variances of the fitted polynomials at year $y$ (Fig. 9b),

- and the scenario uncertainty of a given year $y, S_{y}$, is the variance of the multi-GCM means of each scenario (Fig. 9b) at year $y$.

We use equal weights for all GCMs. Note that this separation into different sources of uncertainty oversimplifies the relations between the different sources, e.g., assuming independence between the sources and no dependence of internal variability on time. Both assumptions cannot be considered as given, e.g., internal variability depends on the GCM formulation and additionally may change over time, if shifts to new climate regimes occur. Since the complex interactions between all involved sources prevent a straight forward disentanglement, one has to keep in mind the inherent limitations of such a separation.

By construction, the total variance of the entire ensemble at a given year $y$ equals the sum of the three uncertainty contributions, $T_{y}=V+M_{y}+S_{y}$ and its square root $\sqrt{T_{y}}$ defines the total uncertainty. The fractional uncertainty, $F_{y}$, of a future year $y$ is defined as the total uncertainty $\sqrt{T_{y}}$ divided by the change, $G_{y}$, between that future year and a reference year calculated from the average of the fitted polynomials of all GCMs and all scenarios of that year (Fig. 9c). If this ratio $F_{y}=\sqrt{T_{y}} / G_{y}$ drops below the value of 1 , the change signal is larger than the uncertainty and, thus, detectable. The year when this happens can be interpreted as "Time of Emergence" (see Wilby, 2006; Hawkins and Sutton, 2012, for related definitions). Note that Hawkins and Sutton (2009) use the more restrictive $90 \%$ confidence interval (approximately $\left.1.65 \sqrt{T_{y}}\right)$ instead of the standard deviation $\left(\sqrt{T_{y}}\right)$.

Figure 10 presents the results of this analysis for the same regions as in Fig. 8 (those with decreasing SPI12) for the drought indices SPI12 and SMA (together with 
their frequency time series of months with SPI $12<-1$ or SMA $<-1$, respectively) and the heat wave index WSDI for comparison. The panels show the total fractional uncertainty, $F_{y}=\sqrt{T_{y}} / G_{y}$, with respect to the reference year 2006, with the topmost black curve. The area beneath is shaded according to the relative uncertainty contributions from the GCMs' formulation $\left(M_{y} / G_{y}\right.$, blue), internal variability $\left(V / G_{y}\right.$, orange), and scenario uncertainty ( $S_{y} / G_{y}$, green).

The projections of changes in the magnitude of SPI12 and SMA (Fig. 10, first and third columns) never reach the critical detection threshold, irrespective of the region. The frequency of drought series according to SPI12 (analysed in the second column) come closer to the detection threshold compared to the SPI12 series itself, but do not cross it either. The same holds for SPI3 (Fig. S6 in the Supplement). Only for frequency of drought series according to SMA (fourth column) and for the Mediterranean, South Africa and Central America/Mexico regions, a detectable change signal is found. Only for these regions a "Time of Emergence" of the change signals can be determined, which in our analysis ranges between 2015 (MED) and 2040 (SAF), although this may be too early given the rather generous definition of total uncertainty of one standard deviation that we display in Fig. 10 (e.g., compared to the $90 \%$ confidence interval applied in Hawkins and Sutton, 2009).

Furthermore, scenario uncertainty plays only a minor role and can in most cases be neglected in relation to internal variability and GCM uncertainty. For the meteorological drought index SPI12, internal variability remains an important (and often the dominant) uncertainty contributor until 2100. In contrast, for projections of soil moisture drought (SMA), uncertainty is only dominated by internal variability over the very first years, while GCM uncertainty becomes strongly dominant after approximately 2030.

These findings stand in contrast to the heat wave projections, measured by the Warm Spell Duration Index (WSDI), for which GCM formulation never contributes significantly to the total uncertainty (last column in Fig. 10). After a short period in which internal variability constitutes the dominant source of uncertainty, total fractional uncertainty drops below 1 no later than 2030 in all regions, and thereafter the clear dominant source of uncertainty is the GHG concentrations scenario. In fact, if one chose, as history will do, one GHG concentrations scenario and, thus, subtracted the GHG concentrations scenario contribution from the total fractional uncertainty, projected changes of heat waves for the end of the 21 st century (which increase, not shown) would be extremely consistent across the GCM simulations, while the likelihood range of drought would be hardly reduced. This comes as no surprise, since the WSDI depends on temperature only (generally the variable with the highest consistency between the GCM simulations), whereas the drought indices depend much more on complex processes and variables (such as precipitation, land surface fluxes and soil moisture) with still uncertain representations in the GCMs (Seneviratne et al., 2010).

I. H. Taylor et al. (2012) apply a similar analysis to a perturbed parameters ensemble, including as additional source of uncertainty the choice of the drought index, which turns out to contribute at least twice as much as all other sources together. However, different indices quantify different drought aspects and their combination does not constitute a source of uncertainty that is comparable to the combination of different GCMs in a multi-model ensemble. It should be noted that Burke and Brown (2008) also assessed the dependence of projected patterns of drought changes on the choice of drought indices, and find that for the regions that we identify as showing robust increases, the increase in drought is independent of the index.

\section{Conclusions}

Drought is one of the most societally relevant weather and climate phenomena, and high-impact droughts from recent years have been highlighted in the literature. However, our analysis of the Standardised Precipitation Index, calculated for the 3 month (SPI3) and the 12 month (SPI12) time scales, shows that at least within this meteorological framework the recent drought events are not exceptional compared to the overall variability in the observation-based time series and the CMIP5 ensemble. Regional SPI3 and SPI12 series of drought hot-spots display hardly any trend over the last decades in observation-based datasets and CMIP5 simulations, but Soil Moisture Anomalies (SMA) from CMIP5 suggest increasing soil moisture (agricultural) drought in some regions, most importantly in the Mediterranean (in agreement with Sheffield and Wood, 2008b; Hoerling et al., 2012a). Other studies (Stahl et al., 2010, 2012) have shown that this trend translates also into river runoff. Further regions of increased drought include South Africa, Central America/Mexico and North East Brazil, reconfirming results in Sheffield and Wood (2008b); Dai (2011). Increases in agricultural drought during the recent past are therefore not driven by decreased precipitation, but by increased evapotranspiration, highlighting that the SPI or more generally meteorological drought, captures only part of the phenomenon.

However, quantifying the terrestrial aspects of drought, in particular, soil moisture and its changes, is by far less straight forward than for the meteorological part. Historical drought trends in more comprehensive indices such as the Palmer's Drought Severity Index, which is considered relevant for soil moisture drought (Sheffield and Wood, 2011), have been shown to depend critically on the assumptions underlying the computation of these indices (Sheffield et al., 2012). Direct measures of (root-zone) soil moisture are available only with insufficient temporal and spatial coverage, or are compromised by issues with data quality and consistency. Many analyses on soil moisture in the literature rely 
on model simulations (e.g., Sheffield and Wood, 2008b; Dai, 2011, and references therein), which, however, as our study shows, simulate a large range of drying and wetting changes. The many sources of uncertainty stress the importance of the regions, where despite these limitations increases have been detected with some reliability over the observational period (such as the Mediterranean, Central America/Mexico, South Africa or North East Brazil).

Large internal variability and a wide likelihood range is also found in GCM projections until the end of the 21st century, inhibiting a robust trend detection in many areas. This holds both for meteorological drought (as quantified by the SPI) and soil moisture drought (measured by SMA). The signals are stronger in the SMA projections compared to SPI, since SMAs integrate effects of increased evaporation in the course of global warming in addition to projected changes in precipitation. Also, the signal-to-noise ratio of increasing drought is higher for frequencies of drought indices below a certain threshold compared to drought magnitudes, although it should be noted that our standardised thresholds have not been related to actual impacts.

Despite the overall large spread of the projections, robust signals emerge in a few regions, namely increased drought in the Mediterranean, South Africa and Central America/Mexico, thus, continuing tendencies already identified for the recent past, in agreement with CMIP3 analyses in Sheffield and Wood (2008a) and Orlowsky and Seneviratne (2012). Changes in soil moisture drought occurrence frequencies even exceed the total uncertainty of the CMIP5 ensemble, with the "Times of Emergence" occurring approximately between 2015 and 2040. On the other hand, some drought hot spot regions of the last decades such as the Sahel, East Africa or South Asia are projected to become less drought-prone, although uncertainties remain large for these regions. In regions such as Central Europe, East Asia or Australia, drought projections range between strong drying and wetting conditions. Extreme drying scenarios are, therefore, about as likely as significantly reduced drought in several regions.

Partitioning the total ensemble uncertainty of future drought projections into contributions from internal variability, GCM formulation and GHG concentrations scenario uncertainty shows mostly negligible contributions from the GHG concentrations scenarios, but large contributions from internal variability for the next decades, especially for SPI. This indicates that there is only limited potential to narrow the likelihood range of near to mid term meteorological drought projections. On the other hand, the total uncertainty for SMA is dominated by uncertainty from GCM formulation already in the near future, which means that in principle GCM improvements could substantially reduce the spread of the projections, although the existing large uncertainty regarding land surface processes constitutes a huge challenge. Ongoing efforts to consolidate existing soil moisture data from in-situ measurements and satellites into consistent data products will enable a much better evaluation of GCMs over the coming years. These new data together with more realistic GCMs will allow for more reliable analyses of soil moisture changes in both past and future.

In summary, our results emphasise the large uncertainty in the quantification and projection of drought on the regional scale. Much of this uncertainty comes from the GCM formulation, which can hopefully be improved once that more exhaustive and consistent data of the land surface become available. Already now, our results show that despite the uncertainty in other regions, droughts have increased in the Mediterranean, Central America/Mexico and South Africa and are projected to increase further, emphasising the need for proactive adaptation planning. In other regions where potential changes remain undetected due to the wide likelihood range of changes, this spread must not be mistaken for low drought risk, since projections for all regions include the possibility of increasing drought, even in cases where the average projections point towards wetter conditions. This is particularly critical as some of these regions (e.g., parts of the US, India, China and Central Europe) are vital for global food production.

\section{Supplementary material related to this article is available online at: http://www.hydrol-earth-syst-sci.net/ 17/1765/2013/hess-17-1765-2013-supplement.pdf.}

Acknowledgements. We acknowledge the World Climate Research Programme's Working Group on Coupled Modelling, which is responsible for CMIP, and we thank the climate modelling groups (listed in Table 1 of this paper) for producing and making available their model output. For CMIP the US Department of Energy's Programme for Climate Model Diagnosis and Intercomparison provides coordinating support and led development of software infrastructure in partnership with the Global Organisation for Earth System Science Portals. We also thank Urs Beyerle and Thierry Corti (C2SM) for support with the downloading and storage of the CMIP5 data. We are grateful to the ETCCDI team at the Canadian Center for Climate Modelling and Analysis for computing and making available the heat wave index WSDI. We acknowledge partial funding from the EU 7th framework programme through the DROUGHT-RSPI (Grant No. 282769) and EMBRACE (Grant No. 282672) projects. We acknowledge the concise and careful reviews by Henny van Lanen and Jamie Hannaford which helped to substantially improve the manuscript. We are also grateful to the Editor for the efficient handling of the review process and the constructive comments.

Edited by: B. van den Hurk 


\section{References}

Adler, R., Huffman, G., Chang, A., Ferraro, R., Xie, P., Janowiak, J., Rudolf, B., Schneider, U., Curtis, S., Bolvin, D., Gruber, A., Susskind, J., Arkin, P., and Nelkin, E.: The version 2 global precipitation climatology project (GPCP) monthly precipitation analysis (1979-present), J. Hydrometeorol., 4, 1147-1167, 2003.

Barriopedro, D., Gouveia, C. M., Trigo, R. M., and Wang, L.: The 2009/10 Drought in China: Possible Causes and Impacts on Vegetation, J. Hydrometeorol., 13, 1251-1267, doi:10.1175/JHM-D11-074.1, 2012.

Burke, E. J. and Brown, S. J.: Evaluating Uncertainties in the Projection of Future Drought, J. Hydrometeorol., 9, 292-299, doi:10.1175/2007JHM929.1, 2008.

Dai, A.: Drought under global warming: a review, Wiley Interdisciplinary Reviews: Climate Change, 2, 1757-7799, doi:10.1002/wcc.81, 2011.

Dai, A.: Increasing drought under global warming in observations and models, Nature Clim. Change, 3, 52-58, doi:10.1038/nclimate1633, 2013.

Dirmeyer, P. A., Schlosser, C. A., and Brubaker, K. L.: Precipitation, recycling and land memory: An integrated analysis, J. Hydrometeorol., 10, 278-288, 2009.

Foley, J. A., Ramankutty, N., Brauman, K. A., Cassidy, E. S., Gerber, J. S., Johnston, M., Mueller, N. D., O'Connell, C., Ray, D. K., West, P. C., Balzer, C., Bennett, E. M., Carpenter, S. R., Hill, J., Monfreda, C., Polasky, S., Rockstrom, J., Sheehan, J., Siebert, S., Tilman, D., and Zaks, D. P. M.: Solutions for a cultivated planet, Nature, 478, 337-342, doi:10.1038/nature10452, 2011.

Friedlingstein, P., Cox, P., Betts, R., Bopp, L., Bloh, W. V., Brovkin, V., Cadule, P., Doney, S., Eby, M., Fung, I., Bala, G., John, J., Jones, C., Joos, F., Kato, T., Kawamiya, M., Knorr, W., Lindsay, K., Matthews, H. D., Raddatz, T., Rayner, P., Reick, C., Roeckner, E., Schnitzler, K. G., Schnur, R., Strassmann, K., Weaver, A. J., Yoshikawa, C., and Zeng, N.: Climate-Carbon Cycle Feedback Analysis: Results from the CMIP Model Intercomparison, J. Climate, 19, 3337-3353, 2006.

Hawkins, E. and Sutton, R.: The potential to narrow uncertainty in regional climate predictionsm, B. Am. Meteorol. Soc., 90, 10951107, 2009.

Hawkins, E. and Sutton, R.: Time of emergence of climate signals, Geophys. Res. Lett., 39, L01702, doi:10.1029/2011GL050087, 2012.

Heim, R.: A review of twentieth-century drought indices used in the United States, B. Am. Meteorol. Soc., 83, 1149-1166, 2002.

Held, I. M., Delworth, T. L., Lu, J., Findell, K. L., and Knutson, T. R.: Simulation of Sahel drought in the 20th and 21st centuries, P. Natl. Acad. Sci., 102, 17891-17896, doi:10.1073/pnas.0509057102, 2005.

Hirschi, M., Seneviratne, S. I., Alexandrov, V., Boberg, F., Boroneant, C., Christensen, O. B., Formayer, H., Orlowsky, B., and Stepanek, P.: Observational evidence for soil-moisture impact on hot extremes in southeastern Europe, Nat. Geosci., 4, 17-21, doi:10.1038/ngeo1032, 2011.

Hoerling, M., Eischeid, J., Perlwitz, J., Quan, X., Zhang, T., and Pegion, P.: On the increased frequency of Mediterranean drought, J. Climate, 25, 2146-2161, 2012a.

Hoerling, M., Kumar, A., Dole, R., Nielsen-Gammon, J. W., Eischeid, J., Perlwitz, J., Quan, X.-W., Zhang, T., Pegion, P., and
Chen, M.: Anatomy of an Extreme Event, J. Climate, online first, doi:10.1175/JCLI-D-12-00270.1, 2012b.

IPCC: Managing the Risks of Extreme Events and Disasters to Advance Climate Change Adaptation. A Special Report of Working Groups I and II of the Intergovernmental Panel on Climate Change, edited by: Field, C. B., Barros, V., Stocker, T. F., Qin, D., Dokken, D. J., Ebi, K. L., Mastrandrea, M. D., Mach, K. J., Plattner, G.-K., Allen, S. K., Tignor, M., and Midgley, P. M., Cambridge University Press, Cambridge, UK, and New York, NY, USA, 2012.

Lenton, T., Held, H., Kriegler, E., Hall, J., Lucht, W., Rahmstorf, S., and Schellnhuber, H.: Tipping elements in the Earth's climate system, P. Natl. Acad. Sci., 105, 1786-1793, 2008.

Lewis, S., Brando, P., Phillips, O., van der Heijden, G., and Nepstad, D.: The 2010 Amazon Drought, Science, 331, 554-554, 2011.

Liu, Y. Y., Dorigo, W. A., Parinussa, R. M., de Jeu, R. A. M., Wagner, W., McCabe, M. F., Evans, J., and van Dijk, A.: Trendpreserving blending of passive and active microwave soil moisture retrievals, Remote Sens. Environ., 123, 280-297, 2012.

Lloyd-Hughes, B. and Saunders, M.: A drought climatology for Europe, Int. J. Climatol., 22, 1571-1592, 2002.

Lyon, B. and DeWitt, D. G.: A recent and abrupt decline in the East African long rains, Geophys. Res. Lett., 39, L02702, doi:10.1029/2011GL050337, 2012.

Marengo, J., Nobre, C., Tomasella, J., Oyama, M., Sampaio de Oliveira, G., de Oliveira, R., Camargo, H., Alves, L., and Brown, I.: The drought of Amazonia in 2005, J. Climate, 21, 495-516, 2008.

McGrath, G. S., Sadler, R., Fleming, K., Tregoning, P., Hinz, C., and Veneklaas, E. J.: Tropical cyclones and the ecohydrology of Australia's recent continental-scale drought, Geophys. Res. Lett., 39, L03404, doi:10.1029/2011GL050263, 2012.

McKee, T. B., Oeskin, N. J. D., and Kleist, J. K.: The relationship of drought frequency and duration to time scales, in: 8th Conference on applied climatology, 179-184, American Meteorological Society, Anaheim, Canada, 1993.

Mitchell, T. and Jones, P.: An improved method of constructing a database of monthly climate observations and associated highresolution grids, Int. J. Climatol., 25, 693-712, 2005.

Monfreda, C., Ramankutty, N., and Foley, J.: Farming the planet: 2. Geographic distribution of crop areas, yields, physiological types, and net primary production in the year 2000, Glob. Biogeochem. Cy., 22, 1-19, 2008.

Monteith, J.: Evaporation and environment, Symp. Soc. Exp. Biol., 19, 205-234, 1965.

Moss, R. H., Edmonds, J. A., Hibbard, K. A., Manning, M. R., Rose, S. K., van Vuuren, D. P., Carter, T. R., Emori, S., Kainuma, M., Kram, T., Meehl, G. A., Mitchell, J. F. B., Nakicenovic, N., Riahi, K., Smith, S. J., Stouffer, R. J., Thomson, A. M., Weyant, J. P., and Wilbanks, T. J.: The next generation of scenarios for climate change research and assessment, Nature, 463, 747-756, 2010.

Mueller, B. and Seneviratne, S.: Hot days induced by precipitation deficits at the global scale, P. Natl. Acad. Sci., 109, 1239812403, 2012.

Orlowsky, B. and Seneviratne, S. I.: Global changes in extreme events: Regional and seasonal dimension, Climatic Change, 110, 669-696, 2012.

Orth, R. and Seneviratne, S.: Analysis of soil moisture memory from observations in Europe, J. Geophys. Res., 117, D15115, 
doi:10.1029/2011JD017366, 2012.

Palmer, W. C.: Meteorological drought, US Department of Commerce, Weather Bureau Washington, DC, USA, 1965.

Peterson, T., Stott, P., and Herring, S.: Explaining extreme events of 2011 from a climate perspective, B. Am. Meteorol. Soc., 93, 1041-1067, 2012.

Poulter, B., Hattermann, F., Hawkins, E., Zaehle, S., Sitch, S., Restrepo-Coupe, N., Heyder, U., and Cramer, W.: Robust dynamics of Amazon dieback to climate change with perturbed ecosystem model parameters, Glob. Biogeochem. Cy., 16, 2476-2495, doi:10.1111/j.1365-2486.2009.02157.x, 2010.

Seneviratne, S. I.: Climate science: Historical drought trends revisited, Nature, 491, 338-339, doi:10.1038/491338a, 2012.

Seneviratne, S. I., Corti, T., Davin, E. L., Jaeger, E. B., Hirschi, M., Lehner, I., Orlowsky, B., and Teuling, A. J.: Investigating soil moisture-climate interactions in a changing climate: A review, Earth-Sci. Rev., 99, 125-161, 2010.

Seneviratne, S. I., Nicholls, N., Easterling, D., Goodess, C., Kanae, S., Kossin, J., Luo, Y., Marengo, J., McInnes, K., Rahimi, M., Reichstein, M., Sorteberg, A., Vera, C., and Zhang, X.: Changes in climate extremes and their impacts on the natural physical environment, in: Managing the Risks of Extreme Events and Disasters to Advance Climate Change Adaptation. A Special Report of Working Groups I and II of the Intergovernmental Panel on Climate Change (IPCC), edited by: Field, C. B., Barros, V., Stocker, T., Qin, D., Dokken, D., Ebi, K., Mastrandrea, M., Mach, K., Plattner, G.-K., Allen, S., Tignor, M., and Midgley, P., 109-230, Cambridge University Press, Cambridge, UK, and New York, NY, USA, 2012.

Sheffield, J. and Wood, E.: Projected changes in drought occurrence under future global warming from multi-model, multiscenario, IPCC AR4 simulations, Clim. Dynam., 31, 79-105, doi:10.1007/s00382-007-0340-z, 2008a.

Sheffield, J. and Wood, E. F.: Global Trends and Variability in Soil Moisture and Drought Characteristics, 1950-2000, from Observation-Driven Simulations of the Terrestrial Hydrologic Cycle, J. Climate, 21, 432-458, doi:10.1175/2007JCLI1822.1, 2008b.

Sheffield, J. and Wood, E. F.: Drought: past problems and future scenarios., Earthscan Publications Ltd, 2011.

Sheffield, J., Wood, E. F., and Roderick, M. L.: Little change in global drought over the past 60 years, Nature, 491, 435-438, doi:10.1038/nature11575, 2012.

Shongwe, M., van Oldenborgh, G., van den Hurk, B., and van Aalst, M.: Projected changes in mean and extreme precipitation in Africa under global warming, Part II: East Africa, J. Climate, 24, 3718-3733, doi:10.1175/2010JCLI2883.1, 2011.

Sillmann, J., Kharin, V. V., Zhang, X., Zwiers, F. W., and Bronaugh, D.: Climate extreme indices in the CMIP5 multi-model ensemble. Part 1: Model evaluation in the present climate, J. Geophys. Res., 118, 1716-1733, doi:10.1002/jgrd.50203, 2013 a.

Sillmann, J., Kharin, V. V., Zwiers, F. W., Zhang, X., and Bronaugh, D.: Climate extreme indices in the CMIP5 multi-model ensemble. Part 2: Future climate projections, J. Geophys. Res., 118, 2473-2493, doi:10.1002/jgrd.50188, 2013b.
Stahl, K., Hisdal, H., Hannaford, J., Tallaksen, L. M., van Lanen, H. A. J., Sauquet, E., Demuth, S., Fendekova, M., and Jódar, J.: Streamflow trends in Europe: evidence from a dataset of nearnatural catchments, Hydrol. Earth Syst. Sci., 14, 2367-2382, doi:10.5194/hess-14-2367-2010, 2010.

Stahl, K., Tallaksen, L. M., Hannaford, J., and van Lanen, H. A. J.: Filling the white space on maps of European runoff trends: estimates from a multi-model ensemble, Hydrol. Earth Syst. Sci., 16, 2035-2047, doi:10.5194/hess-16-2035-2012, 2012.

Sun, C. and Yang, S.: Persistent severe drought in southern China during winter and spring 2011: Large-scale circulation patterns and possible impacting factors, J. Geophys. Res., 117, D10112, doi:10.1029/2012JD017500, 2012.

Taylor, I. H., Burke, E., McColl, L., Falloon, P., Harris, G. R., and McNeall, D.: Contributions to uncertainty in projections of future drought under climate change scenarios, Hydrol. Earth Syst. Sci. Discuss., 9, 12613-12653, doi:10.5194/hessd-912613-2012, 2012.

Taylor, K. E., Balaji, V., Hankin, S., Juckes, M., Lawrence, B., and Pascoe, S.: CMIP5 Data Reference Syntax (DRS) and Controlled Vocabularies, PCMDI, available at: http://cmip-pcmdi. llnl.gov/cmip5/docs/cmip5_data_reference_syntax.pdf (last access: March 2013), version 1.2, 2011.

Taylor, K. E., Stouffer, R. J., and Meehl, G. A.: An Overview of CMIP5 and the Experiment Design, B. Am. Meteorol. Soc., 93, 485-498, doi:10.1175/BAMS-D-11-00094.1, 2012.

Tebaldi, C., Hayhoe, K., Arblaster, J. M., and Meehl, G. A.: Going to the extremes - An intercomparison of model-simulated historical and future changes in extreme events, Climatic Change, 79, 185-211, 2006.

Thornthwaite, C. W.: An approach toward a rational classification of climate, Geogr. Rev., 38, 55-94, 1948.

Van Vuuren, D. P., Edmonds, J., Kainuma, M., Riahi, K., Thomson, A., Hibbard, K., Hurtt, G. C., Kram, T., Krey, V., Lamarque, J.F., Masui, T., Meinshausen, M., Nakicenovic, N., Smith, S. J., and Rose, S. K.: The representative concentration pathways: an overview, Climatic Change, 109, 5-31, 2011.

Wang, G.: Agricultural drought in a future climate: results from 15 global climate models participating in the IPCC 4th assessment, Clim. Dynam., 25, 739-753, doi:10.1007/s00382-005-0057-9, 2005.

Wells, N., Goddard, S., and Hayes, M. J.: A self-calibrating Palmer drought severity index, J. Climate, 17, 2335-2351, 2004.

Wilby, R. L.: When and where might climate change be detectable in UK river flows?, Geophys. Res. Lett., 33, L19407, doi:10.1029/2006GL027552, 2006.

Xie, P. and Arkin, P.: Global precipitation: A 17-year monthly analysis based on gauge observations, satellite estimates, and numerical model outputs, B. Am. Meteorol. Soc., 78, 2539-2558, 1997.

Zhang, X., Zwiers, F., Hegerl, G., Lambert, F., Gillett, N., Solomon, S., Stott, P., and Nozawa, T.: Detection of human influence on twentieth-century precipitation trends, Nature, 448, 461-465, 2007. 